\title{
CORPUS Corpus
}

Archivos virtuales de la alteridad americana

Vol 3, No $1 \mid 2013$

Enero / Junio 2013

\section{La Misión Indígena San Francisco Solano de Tacaaglé en las tierras fiscales de Formosa (1900-1950)}

Gabriela Dalla Corte

\author{
(2) OpenEdition \\ Journals \\ Edición electrónica \\ URL: http://journals.openedition.org/corpusarchivos/212 \\ DOI: 10.4000/corpusarchivos.212 \\ ISSN: 1853-8037 \\ Editor \\ Diego Escolar
}

Referencia electrónica

Gabriela Dalla Corte, «La Misión Indígena San Francisco Solano de Tacaaglé en las tierras fiscales de Formosa (1900-1950) », Corpus [En línea], Vol 3, No 1 | 2013, Publicado el 15 junio 2013, consultado el 19 abril 2019. URL : http://journals.openedition.org/corpusarchivos/212 ; DOI : 10.4000/ corpusarchivos. 212

Este documento fue generado automáticamente el 19 abril 2019.

Licencia Creative Commons: Atribución-NoComercial 2.5 Argentina (CC BY-NC 2.5 AR) 


\title{
La Misión Indígena San Francisco Solano de Tacaaglé en las tierras fiscales de Formosa (1900-1950)
}

\author{
Gabriela Dalla Corte
}

\section{NOTA DEL EDITOR}

Fecha de recepción del original: 28-01-2013

Fecha de aceptación para publicación: 02-05-2013

\section{Introducción}

1 El espacio formoseño de la zona "desértica" establecida a orillas del río Pilcomayo, en la frontera con Paraguay, fue ocupado por los Misioneros Franciscanos durante la primera mitad del siglo XX. ${ }^{1}$ En base al Art. 100 de la Ley № 817 de Colonización firmada por el Poder Ejecutivo de la República Argentina el 19 de octubre de 1876 -cuyo objetivo era fomentar los recursos locales, en especial el ganado y la producción de azúcar-, el Gobernador del Territorio Nacional de Formosa insistió en la creación de "Misiones o Colonias Indígenas" para salvaguardar a las "tribus de indios", en especial a la del Cacique Valdivieso. $^{2}$

La Misión Indígena Franciscana destinada a los aborígenes tobas y pilagás del espacio fronterizo del Territorio Nacional de Formosa, fue inaugurada en el año 1901 en el paraje que el Fray Zacarías Ducci registró con el nombre de riacho Nococolda (también Ñococaldá, así como Ñocacolda según Fray Serafín Iturralde), y que en voz toba significa "matanza de los muchachos". Esta zona de 40.000 hectáreas otorgadas por el Poder Ejecutivo a la Orden Franciscana debía garantizar la expansión territorial, productiva y comercial de la República Argentina a través de sus "transformados colonos indígenas". $\mathrm{Al}$ año siguiente, y como consecuencia de la ancestral inundación del río Pilcomayo, la 
Misión Indígena fue trasladada a la zona "del Chajá" o de "multitud de Chajá", también llamada Tacaaglé (Tacaag-lé, Takagale, Tacaaggal'le, Tagalé), y se le concedió una superficie de 60.000 hectáreas para garantizar la producción de azúcar.

3 Finalmente, la Dirección General de Territorios Nacionales valoró negativamente la falta de recursos y de alimentos, así como la pérdida de la cosecha por la seca de las sementeras. Se diseñó entonces una tercera ubicación para la Misión Indígena Franciscana a ambos lados del riacho El Porteño. En consecuencia, el 20 de marzo y el 19 de junio de 1914 el Ministerio del Interior modificó los decretos firmados el 10 de abril y el 4 de mayo de 1900: los Misioneros Franciscanos, por ende, se trasladaron a una zona llamada Sataléc del riacho Porteño, para hacerse cargo de 40.000 hectáreas y de 140 familias tobas y pilagás. En este proceso histórico, la Misión Indígena recibió el nombre definitivo de "San Francisco Solano de Tacaaglé".

4 Ahora bien: desde el momento en que se inauguró el Ferrocarril de Formosa a Embarcación (F.C.F.E.), con acercamiento a la zona de la Misión Indígena del riacho El Porteño, se produjeron intensos conflictos entre los Misioneros, el Gobernador del Territorio Nacional de Formosa, y el Poder Ejecutivo de la República Argentina. Esta es la base que nos interesa analizar aquí a través de la documentación histórica conservada en la Biblioteca y Archivo Históricos de la Provincia Franciscana de San Miguel, en el Museo Conventual de San Carlos Borromeo ubicado frente al Campo de la Gloria de San Lorenzo, Provincia de Santa Fe (en adelante BACSC). Se trata precisamente de una historia que articula la gestión misionera, la gubernamental y la organización de un espacio definido como "Diócesis de Santa Fe" que incluyó los Territorios Nacionales de Chaco y Formosa, así como la zona chaqueña y pampeana de la Provincia de Santa Fe.

5 A través de la lectura de estas fuentes documentales, abordamos el extenso expediente № 2665-F-1896 que garantizó la fundación de la Misión del Pilcomayo en 1901, y su traslado y ampliación en el año 1902. ${ }^{3}$ Seguidamente nos basamos en la "Carpeta Tacaaglé" incluida en la Caja 47 de la Biblioteca y Archivo Históricos de la Provincia Franciscana de San Miguel, la cual unifica el expediente № 93.033 gestado entre la Orden Franciscana y el Gobierno Nacional argentino desde 1900 a $1932 .{ }^{4}$ Dicha carpeta fue solicitada por Fray Pedro Iturralde al Ministerio de Agricultura, y trasladada al Convento de San Carlos Borromeo de San Lorenzo en junio de 1932, con la intención de salvaguardar la Misión de Tacaaglé y la vida de los indígenas tobas y pilagás, frente a la inauguración del Ferrocarril de Formosa a Embarcación (F.C.F.E.), el cual por entonces se encontraba en proceso de incorporación al Ferrocarril Central Norte Argentino (F.C.N.A.). ${ }^{5}$

Con la intención de demostrar el escaso conocimiento que se tenía a inicios del siglo XX sobre la zona del "salvaje e indómito" río Pilcomayo (Gordillo, 2001; Teruel, 2011), este artículo también incluye diversos croquis elaborados entre 1899 y 1915 por la Dirección de Tierras y Colonias, así como el esquema que hizo Fray Pedro Iturralde en 1917. Los croquis indicaron la ubicación de la Misión, sus traslados, así como su distribución interna, y se elaboraron con escasa precisión ante la falta de instrumentos geométricos. Paralelamente resolvieron la disputa surgida entre el Colegio de San Carlos Borromeo de la Diócesis de Santa Fe, que destinó sus esfuerzos a la Misión de Laishí (Dalla-Corte, 2012), y el Colegio de la Merced de la Provincia de Corrientes, que inauguró la Misión del Pilcomayo (Dalla-Corte y Vázquez, 2011), ambas establecidas en el Territorio Nacional de Formosa. Cabe señalar que la Misión Indígena de Nueva Pompeya del Territorio Nacional del Chaco, por su parte, dependió del Colegio Apostólico de San Diego (Convento San Francisco) de la Provincia de Salta. ${ }^{6}$ En el año 1914, precisamente en el momento en que 
se decidió el último traslado de la Misión de Tacaaglé, la Orden Franciscana fusionó los tres Colegios vinculados a las tres Misiones Indígenas gestadas en los Territorios Nacionales de Chaco y Formosa, para dar forma a la Comisaría Provincial de San Miguel Arcángel de Misioneros Franciscanos de la República Argentina.

7 Sobre esta base, el primer apartado de este artículo se centra en la intensa unión que se gestó entre el Gobierno Nacional, el Gobernador del Territorio Nacional de Formosa y los Misioneros Franciscanos, para la creación de una Misión Indígena. En este caso nos interesa describir la discusión que se produjo entre los propios franciscanos al debatir sobre la fundación y dirección de una Misión y Colonia de Indios del Territorio Nacional de Formosa, en manos de los Misioneros Franciscanos del Colegio de la Merced de la Provincia de Corrientes, aprovechando la colaboración del Cacique Valdivieso, frente al Colegio Apostólico de San Diego de la Diócesis de Santa Fe.

8 El segundo apartado aborda los inicios de la Misión Indígena del río Pilcomayo el 13 de julio de 1900. Siguiendo los principios del Art. 100 de la Ley General de Colonización del 19 de octubre de 1876 (Lagos, 2000, 2003), y siguiendo los dictámenes de la Dirección de Tierras y Colonias del Ministerio del Interior (Borrini, 1997), el Presidente de la República Argentina decretó la concesión de 40.000 hectáreas. Resulta también sugerente el hecho de que este Decreto otorgase a los indígenas la posibilidad de recibir el título de propiedad de un lote rural de cien hectáreas, habiendo residido en la Misión durante diez años, mientras impuso la obligación de los Misioneros de hacerse cargo de más de 125 familias indígenas al nombrar al Comisario establecido en la nueva Misión Indígena como "delegado especial" del Gobierno Nacional.

9 El tercer apartado se centra en los traslados que se produjeron, primero en el año 1902 hacia la zona de Tacaaglé (y aumentando la concesión a 60.000 hectáreas), y después, hacia el riacho El Porteño entre 1914 y 1916 (y volviendo a la concesión de 40.000 hectáreas). El objetivo es discutir en torno a la supuesta "nacionalización" del territorio chaqueño formoseño establecido entre los ríos Pilcomayo y Bermejo (Gordillo, 2007), que quedó en manos argentinas a partir de la Guerra de la Triple Alianza contra Paraguay (Dalla-Corte, 2009).

10 La finalidad de la Misión Indígena formoseña de Tacaaglé cierra este artículo con la intención de contrastar la expansión económica de la zona formoseña frente a la población originaria guaycurú. Para ello se menciona el terrible conflicto que mantuvo la Orden Franciscana con el Gobierno Nacional desde 1916, momento en que el Gobernador de Formosa cuestionó la propia existencia de la Misión de Tacaaglé, hasta el año 1931, cuando la línea del Ferrocarril de Formosa a Embarcación (F.C.F.E.) llegó precisamente a Embarcación para unirse al Ferrocarril Central Norte Argentino (F.C.N.A.).

11 Lo que aquí proponemos es un esbozo del ambiente singular en el que se desenvolvieron Misioneros Franciscanos y "colonos indígenas" de Tacaaglé, todo ello en el marco de la "nacionalización" y "civilización" de los aborígenes tobas y pilagás. A través de la investigación histórica, pretendemos ofrecer algunas claves sobre la organización del Estado-Nación en la República Argentina a partir de la integración del mundo franciscano y del mundo indígena (Teruel, 2005). La elección de la dimensión espacial es fruto de la escasa atención que recibieron las Misiones Franciscanas formoseñas, tanto la de Laishí como la del propio Tacaaglé. En este caso, las diversas ubicaciones de la Misión, efectuadas en la primera mitad del siglo XX en la frontera argentino-paraguaya, representan una región de estudio que conforma un caso histórico abordado parcialmente desde las ciencias sociales. Las investigaciones llevadas adelante desde la 
historia y la antropología por Girbal-Blacha, Lagos, Wright, Teruel, y en especial el sentido otorgado por Gordillo a su obra titulada Nosotros vamos a estar acá siempre (2005), permiten apreciar que se trata de un rico campo de estudios. En mi propia investigación, el objetivo es reconstruir los criterios, mecanismos y estrategias utilizados por los grupos socio-políticos (en este caso, por el Gobernador de Formosa, por el Poder Ejecutivo y por los propios empresarios paraguayos y argentinos establecidos en el Territorio Nacional formoseño), en conjunción o en disputa con los grupos indígenas tobas y pilagás, y con la propia Orden Franciscana. Como parte de las investigaciones de la historia regional argentina, las disputas por el ámbito territorial nos permiten observar el ordenamiento político, económico, cultural y social, así como las vicisitudes jurídicas y reglamentarias experimentadas por Misioneros y aborígenes de la zona del Pilcomayo durante sus diferentes traslados. Las tentativas para lograr un asentamiento definitivo en un espacio regional, colindante a inicios del siglo XX con la concesión de Elisa (Elizabeth Alicia) Lynch, guían la reflexión sobre las dificultades sobrellevadas a nivel local frente a los propios poderes locales y al centralismo estatal.

\section{1.- La disputa por las tierras fiscales de la Misión Indígena y del Cacique Valdivieso}

El origen de la Misión de Tacaaglé data del 18 de agosto de 1896, momento en que el Gobernador de Formosa, el Coronel José María Uriburu, acompañado por Juan Masferrer, elevaron una interesante propuesta al entonces Ministro del Interior, Norberto Quirno Costa, señalándole la necesidad de crear una colonia indígena en las costas del río Bermejo para garantizar el futuro del Ferrocarril de Formosa a Embarcación (F.C.F.E.), por entonces en proceso de construcción:

"La ubicación de ella no sería ninguna más oportuna, que la de los terrenos de la concesión caduca de Don Máximo Ruiz (80.000 hectáreas), situadas en las costas mismas del Bermejo, en lugares ferocísimos, altos, atravesados por los riachos, con lagunas y aguadas permanentes, frente al pueblo y Fuerte Presidencia Roca, cabecera de una línea férrea proyectada (Ñanducito), con guarnición permanente, reservas fiscales pertenecientes al Chaco Austral, puerto natural sobre Río Navegable, lugar de gran caza y pesca y centro de población indígena, mansa, aunque entregada a la barbarie, y sucumbiendo al peso de su abandono y enfermedades. Tengo el honor de indicar esta ubicación, por ser terrenos que personalmente conozco y que infinidad de veces he recorrido, llevando ya en la mente el Proyecto que hoy someto a la ilustrada consideración de Vuestra Excelencia". ${ }^{\circ}$

13 Aceptado este proyecto por el Coronel José María Uriburu, se inició la creación de una Colonia Indígena en el territorio chaqueño de la Gobernación de Formosa. Inicialmente la idea era ubicar una única Misión Indígena en ambas márgenes de la costa del río Bermejo, aprovechando el apoyo de la tribu toba liderada por el Cacique Valdivieso. Pero Ramón B. Castro, miembro de la Comisión de Tierras y Colonias, señaló que:

"En ambas márgenes no hay tierra libre, sino muy arriba y en condiciones inferiores a las que formaba la concesión caduca de don Máximo Ruiz, de 80.000 hectáreas...Tomándose como base para esa población la tribu del Cacique Valdivieso, sin indicar paraje especial, manifestando sólo que debe tener 40.000 hectáreas, y que el Señor Perito de la Comisión de Límites debe indicar el lugar donde debe establecerse dicha Colonia (Indígena)". ${ }^{9}$ 
Días después, se dio a conocer el informe de Inspección General que remarcó la importancia de la iniciativa del Gobernador de Formosa, la cual, "digna de encomio", se debía proyectar primero como colonia para estudiar el terreno, y después de ello solicitar su creación. En este sentido, el objetivo era:

"Propender al adelanto y población de regiones desiertas y traer á la vida civilizada las tribus indígenas, que viven errantes, ha sido siempre el propósito de los Gobiernos Argentinos, así que no puede menos de aplaudirse la iniciativa del Sr. Gobernador de Formosa. En cuanto a la ubicación, que podría darse a la colonia, el Sr. Gobernador mismo la indica, y está con él de acuerdo la Sección Tierras y Colonias, según su informe. Esta Sección no puede aconsejar la ubicación ni señalar otra, por cuanto no tenido ocasión visitar aquellos lugares, ni conoce tampoco la índole y carácter de los indígenas de aquella región, para poder decir si conviene la creación de colonias pastoriles o agrícolas, según sean ellas inclinadas a una u otra cosa. Es cuanto puedo decir como respuesta al informe que se me ordena". ${ }^{10}$

Desconocida la zona formoseña, la Sección de Tierras y Colonias comunicó al Ministerio de Agricultura la imposibilidad de instaurar de manera definitiva el espacio territorial para una "Colonia Indígena", ya que contaba con vías de comunicación y de centros poblados que lo rodeaban. No obstante, estaba claro que la tribu de indios del Cacique Valdivieso sería el "núcleo de la nueva colonia" que deseaba conformar el propio Gobernador de Formosa. ${ }^{11}$ Frente a esta difícil situación, los Padres Misioneros Franciscanos del Colegio Apostólico de Propaganda del Colegio de la Merced de Corrientes (representados por el Comisario General de Misioneros Franciscanos, Fray Salvador Mazza) dirigieron una interesante solicitud a la Comisaría General de Misioneros Franciscanos de la República Argentina. En esa solicitud consta el apoyo al Gobernador de Formosa José María Uriburu para fundar una "Reducción o Colonia Indígena" en ese Territorio Nacional. Llamativamente, los propios franciscanos de la Provincia de Corrientes señalaron las bases de la actuación de los Misioneros en la región formoseña, que el propio Gobernador debía hacer llegar al Gobierno Nacional con la finalidad de elegir un definitivo territorio formoseño. Estos fueron los pedidos incondicionales de los franciscanos:

“1.-Que el Excelentísimo Gobierno Nacional dé en propiedad y con títulos legales a la colectividad o Comunidad de los Indios, un área de terreno bien deslindado y amojonado, proporcionado al número de indios que deben formar la Colonia.

2.-Que dicho terreno esté situado en un lugar aparente bajo todo respecto, para establecer la Colonia; es decir, que sea alto, libre y seguro de las inundaciones, sano, que tenga monte para madera de construcción, campos para labranza y abundancia de aguas.

3.-Que el Excelentísimo Gobierno Nacional vote una suma, a lo menos como la que votó para la Colonia de Tartagal, para la instalación de dicha Colonia, construcción de casa, escuela, capilla, compra de animales, herramientas, semillas, etc.

4.-Que el mismo Excelentísimo Gobierno Nacional asigne una subvención mensual a cada Misionero para su alimentación, vestido, etc., como también un sueldo mensual para un maestro o maestra de escuela, una vez que se matriculen treinta niños a lo menos.

5.- Que los Misioneros gocen de una perfecta independencia de toda autoridad subalterna, para gobernar con leyes propias y reglamentos adecuados (como se practica en las Misiones de Bolivia y otras partes), a los indios, y administrar la Colonia, hasta que se halle en condiciones de poder ser entregada al Gobierno de la autoridad civil.

6.- Que nadie pueda vender ni comprar, a los indios, cosa alguna, ni sacar a éstos de la Colonia, sin intervención, aprobación y licencia de los Misioneros. 
7.- Que el Excelentísimo Gobierno Nacional dé ración diaria a los indios de doce años arriba que se reúnan y permanezcan en la Colonia, como lo hace con los soldados, y esto durante solamente los dos primeros años.

8.- Finalmente, que el Excelentísimo Gobernador del Territorio preste auxilio a los

Padres Misioneros, siempre que estos lo necesitaren, y justamente se lo pidieren". ${ }^{12}$

Como vemos, el ofrecimiento de los franciscanos para fundar una "Colonia o Reducción Indígena” en Formosa, reclamó una retribución mensual para los Padres Misioneros, el nombramiento de un maestro de escuela anexo a la Misión, y el racionamiento para los indígenas mayores de doce años durante dos años, con la finalidad de garantizar su aprendizaje para el trabajo impuesto por el propio Poder Ejecutivo. Fue entonces cuando el Gobernador Uriburu consignó en su informe enviado al Gobierno Nacional que dicha "Colonia Indígena" se debía crear en los "confines de Bolivia, bajo la base del Cacique Valdivieso". De este modo, si se optaba por un terreno distante al río Bermejo, y si se utilizaba la antigua concesión de Máximo Ruiz, era seguro el aislamiento de esta futura Misión Indígena).

Ante esta posibilidad, la única solución era instalar un Fortín guarnecido por fuerzas del Regimiento 12 de Caballería, bajo el mando del propio Gobernador de Formosa, que al mismo tiempo que cumpliría la tarea atribuida a las fuerzas destacadas en Fortines (Spota 2009), darían seguridad personal a los Misioneros Franciscanos. La excelencia del terreno de la zona del río Pilcomayo, según el Gobernador José María Uriburu, se debía a la agrupación de indios y al caudal de agua que reunía el territorio concedido anteriormente a Máximo Ruiz, precisamente en la zona fronteriza con la República del Paraguay:

"Son indígenas los que allí viven, que no están en contacto alguno con lugares poblados; los únicos que molestan con sus correrías al Territorio y es uno de los pasos más frecuentados entre este Chaco y el Austral. En el porvenir, y ya creada la Colonia, podrían radicarse familias extranjeras, que con sus costumbres y ejemplo, concluyesen de asimilar a nuestra civilización a los indios que se trata de reducir...creo firmemente que de crearse esta Colonia, tendría, por el hecho entre otros de estar situada sobre el río navegable, mayor porvenir que las mediterráneas, instaladas en las fronteras de Bolivia, por lo que me permito interesar muy especialmente la atención del Señor Ministro". ${ }^{13}$

En honor al posible adelanto del Territorio Nacional de Formosa, y gracias a la aportación de los Misioneros Franciscanos establecidos en el Colegio de la Merced de la Provincia de Corrientes, los responsables de la Sección de Tierras y Colonias apoyaron la creación de una "Colonia Indígena" para atraer "con actos de civilización y protegiéndolos como se desea a los salvajes que todavía son el azote y el terror de aquellos apartados lugares". ${ }^{14}$ Con la intención de salvaguardar "los últimos restos de las tribus de indios que en las correrías de su vida nómade, son aún perjudiciales y constituyen todavía un peligro para los vecinos trabajadores de esas regiones", ${ }^{15}$ el Gobierno Nacional aseguró la creación de la Misión Indígena, en las costas del río Bermejo. ${ }^{16}$ Finalmente, el Ministerio del Interior apoyó la iniciativa del Gobernador de Formosa, el Coronel José María Uriburu. ${ }^{17} \mathrm{La}$ decisión definitiva fue establecer la Colonia Indígena en uno de los únicos terrenos disponibles, precisamente en la zona del río Bermejo. Por ello, en julio de 1899 José S. Sarhy elaboró un croquis sobre la ubicación de la concesión caducada de Máximo Ruiz, que podía quedar en manos de la Misión Indígena de los franciscanos en la zona del río Bermejo (Imagen № 1). ${ }^{18}$ 
Imagen No 1.- BACSC, Caja 47: “Copia Fiel”, Croquis elaborado por José S. Sarhy, Dirección de Tierras y Colonias, Primera División de Geodesia, Buenos Aires, República Argentina, 4 de julio de 1899.

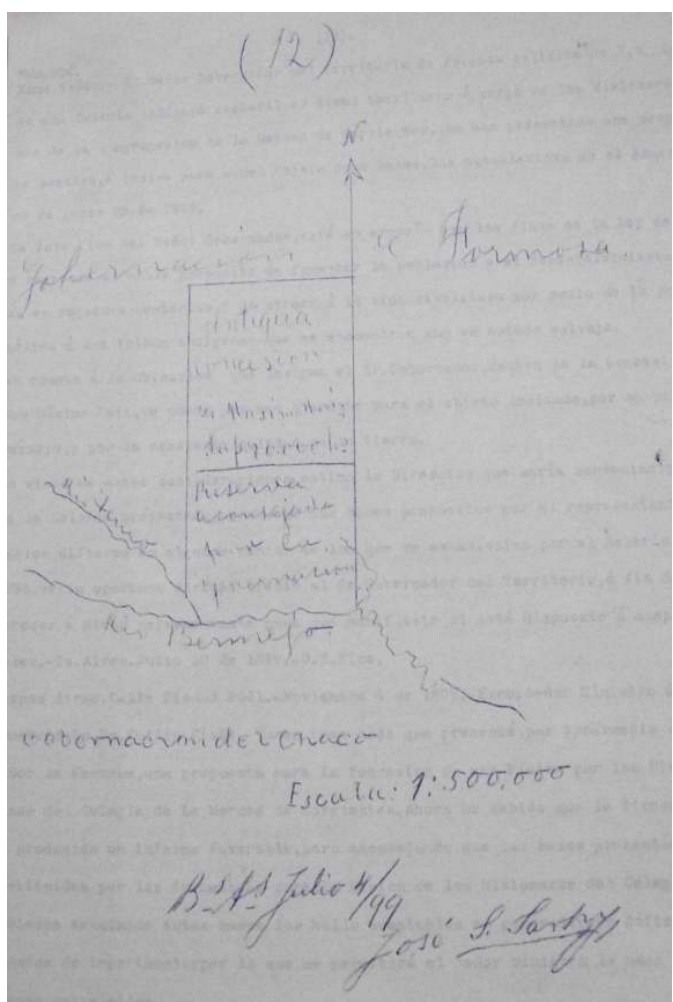

BACSC, Caja 47: "Copia Fiel”, Croquis elaborado por José S. Sarhy, Dirección de Tierras y Colonias, Primera División de Geodesia, Buenos Aires, República Argentina, 4 de julio de 1899.

Ahora bien: quien presentó la propuesta de fundar una Misión Indígena ante el Gobernador de Formosa fue el Comisario General de Misioneros Franciscanos Fray Salvador Mazza, junto a su secretario, Fray Enrique Biagini. En noviembre de 1899, Fray Mazza recibió el informe favorable del Ministerio de Agricultura y Comercio para establecer una Colonia Indígena, pero también tomó conocimiento de que la Misión dejaría de depender de los Misioneros Franciscanos del Colegio de La Merced de la Provincia de Corrientes, y sería ejecutada por los Misioneros del Colegio de San Carlos Borromeo de San Lorenzo en la Provincia de Santa Fe.

Tras aceptar a regañadientes este cambio, el Comisario General Fray Salvador Mazza cuestionó los escasos fondos atribuidos a los Misioneros Franciscanos para hacerse cargo de 150 familias indígenas. Llamó la atención de que el Estado atribuyese un fondo tan escaso para los indígenas ( $500 \$ \mathrm{~m} / \mathrm{h}$ mensuales), y que rechazara otorgar a los Misioneros un subsidio para sus necesidades y para las del culto. De hecho, el propio Comisario General solicitó que cada familia indígena recibiese $10 \$ \mathrm{~m} / \mathrm{n}$ mensuales para garantizar "la obra civilizadora de la Reducción de Indios". La discusión más importante fue que, si aceptaba que los Misioneros del Colegio de San Carlos sustituyesen a los Misioneros Franciscanos de su dependencia (colegio de La Merced de Corrientes), no podía consentir la fundación de una Misión tan pobre a nivel nacional, ya que sería imposible llevar adelante el proyecto de civilizar y nacionalizar a los tobas y pilagás de la zona formoseña. 
21 Finalmente, el Prefecto de Misiones del Colegio de San Carlos Borromeo de la Diócesis de Santa Fe, Fray Pedro Iturralde, consiguió hacerse cargo de la Misión Indígena de Formosa que en poco tiempo se llamó Misión de Laishí. ${ }^{20}$ El 10 de noviembre de 1899 se habilitó el cumplimiento de la resolución gubernamental, ${ }^{21}$ que decretó el origen de la Misión de Laishí el 10 de abril de 1900.

\section{2.- El inicio de la Misión del Pilcomayo y las tierras de Elisa (Elizabeth Alicia) Lynch}

Pocos meses después, el 9 de mayo de 1900, el Misionero Franciscano del Colegio de la Merced de Corrientes, Fray Terencio Marcucci, se presentó ante Martín García Merou, el Ministro de Agricultura, para cuestionar el cambio del Colegio que debía dirigir la futura Misión del Territorio Nacional de Formosa. Presentó entonces la propuesta de que el Colegio de la Merced instalara una Colonia Indígena en unas 40.000 hectáreas ubicadas en ambos costas del río Pilcomayo. Su objetivo era recibir este novedoso terreno, utilizando como modelo la concesión de tierras otorgadas por el Decreto del 10 de abril de 1900 a favor del Colegio de San Carlos Borromeo de la Provincia de Santa Fe.

Para conseguir esta distribución de los territorios formoseños en manos de los Misioneros Franciscanos de Corrientes y de Santa Fe, el Comisario General Fray Gabriel Grotti le otorgó facultad en el nombre de Dios a Fray Terencio Marcucci, por entonces establecido en la "zona chaqueña argentina", para trasladarse a las capitales de las provincias de Corrientes, Buenos Aires y Santa Fe, con la finalidad de tratar "asuntos urgentes de las mismas Misiones, y representarnos...en demás puntos ante las autoridades civiles y religiosas". ${ }^{22}$ Poco después, Fray Terencio Marcucci escribió al Ministro de Agricultura Martín García Merou:

"He hallado un terreno aparente para dicha Misión, y numerosas indiadas, que están dispuestas a reducirse a la vida de la civilización, abandonando la errante que llevan lo que nos ha inducido a solicitar como lo solicito de Vuestra Excelencia a nombre del Reverendo Padre Prefecto Fray Gabriel Grotti". ${ }^{23}$

La solicitud del Colegio de la Merced de Corrientes de ubicar espacialmente una nueva Misión Indígena, llegó a las manos de la Dirección de Tierras y Colonias. ${ }^{24}$ Poco después, P. Piñeiro Sorondo representó a la División de Geodesia, y registró la existencia de 40.000 hectáreas de tierras libres, fiscales y fuera de mensura, que estaban ubicadas "aguas arriba y aguas abajo" (en los dos márgenes) del río Pilcomayo. Al concentrar el interés en la intersección del brazo sur del río mencionado, la línea límite Oeste era la concesión de tierras de Elisa Lynch, la cual se encontraba en proceso de nulidad ante los Tribunales Ordinarios. ${ }^{25}$ Por ello, en junio de 1900 Antonio J. Carballo presentó dos croquis sobre la ubicación de la futura Misión Indígena del Pilcomayo en manos del Colegio de la Provincia de Corrientes. ${ }^{26}$ Carballo dibujó la zona del brazo norte del río Pilcomayo que sumaba 20.000 hectáreas, dividida por el brazo sur del mismo río con otras 20.000 hectáreas. Lo más significativo es que las 40.000 hectáreas concedidas a la Misión Franciscana en el río Pilcomayo, quedaron a un costado de la concesión de Elisa Lynch, todavía vigente, y la de N. Godoy, "hoy fiscal", ambas concesiones divididas por el brazo sur del río Pilcomayo. Como vemos, los Misioneros finalmente se ubicaron al costado de la concesión de tierra de Elisa Lynch, precisamente la compañera del Mariscal Francisco Solano López el cual gobernó Paraguay entre 1862 y 1870, es decir, en plena Guerra de la Triple Alianza que estalló entre 1865 y 1870 (Imagen № 2). 
Imagen $\mathrm{N}^{\circ} 2$

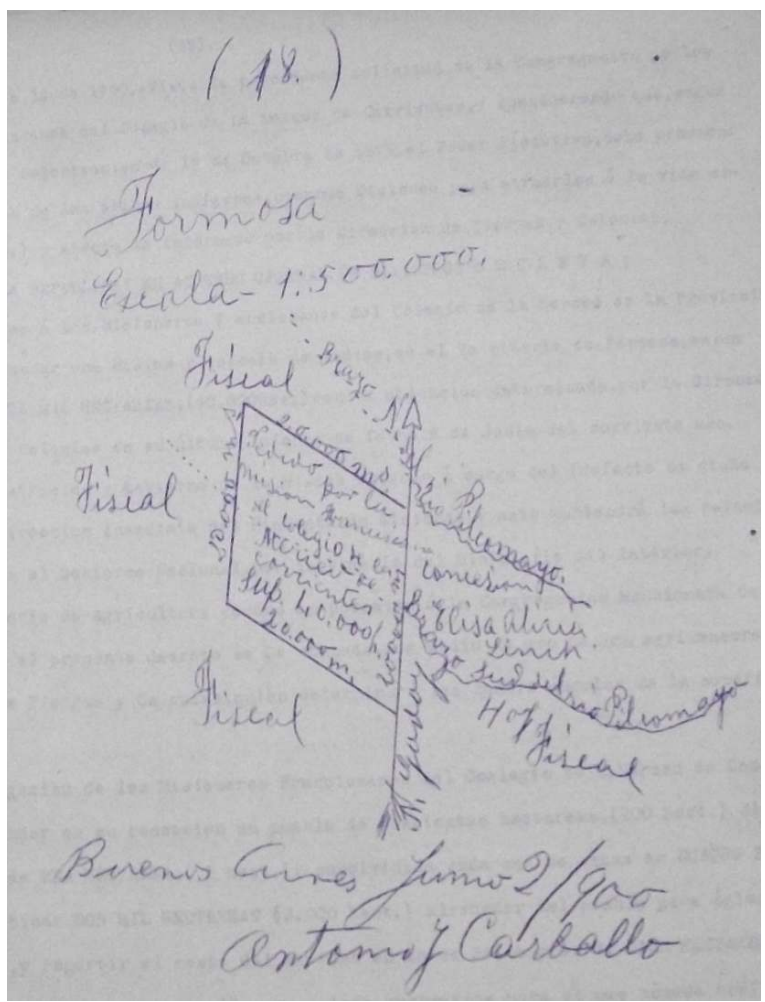

BACSC, Caja 47: "Copia Fiel", Croquis de Antonio J. Carballo de la zona solicitada por la Misión Franciscana del Colegio de la Mercedes de Corrientes (Prefecto de las Misiones Fray Gabriel Grotti), superficie 40.000 hectáreas, río Pilcomayo, entre brazo norte y brazo sur del río Pilcomayo, GEODESIA, en contacto con la tierra concedida a Elizabeth Alicia Lynch, hoy fiscal, 2 de junio de 1900.

Ahora bien, tanto para la Misión del Colegio de San Carlos Borromeo (Laishí), como para la Misión del Pilcomayo (Tacaaglé), la Dirección de Tierras y Colonias de la República Argentina incumplió con su obligación de mensurar los terrenos otorgados. Los propios miembros de la División afirmaron que contaban con un escaso personal para llevar los trabajos de mensura que les habían encomendado, tanto desde la Provincia de Córdoba como desde el Territorio Nacional de Chubut. ${ }^{27}$ Por ello, el Decreto del 20 de noviembre de 1900 dejó sin efecto parte del Decreto del 10 de abril de 1900: a partir de entonces, la mensura quedó en manos de los Misioneros Franciscanos. ${ }^{28}$

Con esto en manos, el Misionero Fray Terencio Marcussi, apoyado por el Prefecto de Misiones del Colegio de La Merced de Corrientes, se contactó con los Caciques tobas y pilagás del Territorio de Formosa. Según Fray Marcucci, los Caciques "tenían bajo su mando como a más de 2.000 indios, con el objetivo de fundarles una Misión Conversora sobre la margen derecha del Pilcomayo". Fray Marcucci les prometió iniciar la marcha hacia la frontera con el Paraguay para los primeros días de noviembre de 1900, con el propósito de cumplir con la "obra civilizadora y humanitaria". ${ }^{29}$

De acuerdo a los escritos elaborados por Fray Guido Depedri desde el Convento de Corrientes, Fray Marcucci se contactó con los Caciques (Quijada, 2011) llamados Doccidí, Cogaiquí y Pichón, y "lleno de abnegación, exponiéndose a toda clase de privaciones y peligros, se trasladó al punto llamado riacho Nococolda, sobre la margen derecha del brazo occidental del Pilcomayo". Permaneció tres años con grandes dificultades por la 
falta de un sistema de transportes que recibir los recursos necesarios, y sus trabajos nunca contaron con el apoyo de la propia Dirección de Tierras y Colonias. ${ }^{30}$

La primera dificultad de la Misión fue la falta del dinero acordado entre los Misioneros y el Gobierno Argentino: el 13 de agosto de 1901 se presentó Fray Pedro Iturralde como representante del Prefecto Fray Grotti. Hizo llegar al Ministro de Agricultura, Wenceslao Escalante, la primera crítica sobre el incumplimiento ministerial que impedía llevar adelante la operación de deslinde, así como la toma de posesión de las tierras otorgadas. Fray Pedro Iturralde estaba convencido de que:

"La falta de dinero acordado por este decreto y los Misioneros, confiados en que se les haría esta entrega, fueron a fundar la Misión, se han establecido provisoriamente en un terreno que, creen, será el destinado a este fin, pero no lo saben con seguridad. Esta incertidumbre les impide dar a sus trabajos el impulso que sería de desear, y la Misión permanecerá estacionaria, mientras no se resuelva esta dificultad". ${ }^{31}$

\section{3.- De la Misión del Pilcomayo a la Misión San Francisco Solano de Tacaaglé}

Otorgada la ocupación sobre el río Pilcomayo, llegó el momento de solicitar la ampliación de la superficie de la Misión Indígena en la que convivían especialmente los aborígenes tobas y pilagás. Como veremos, el Ministro Wenceslao Escalante otorgó a los Misioneros 20.000 hectáreas más, gracias al decreto fechado el 15 de noviembre de 1902 que reconoció la inundación del río Pilcomayo en la zona de la Misión Indígena que afectó cuatro leguas de la zona chaqueña, y arrasó todo lo existente, en particular la Capilla, las casas, los corrales y los alambrados. También ahuyentó a los indígenas al dispersar la hacienda, dejando solo y sin recursos al Misionero Fray Marcucci junto a dos peones. Esta situación fue descrita especialmente por Fray Pedro Iturralde:

“(Fray Marcucci) se puso al habla con el Cacique Monocoidí y, como Misionero, durante diez años a tratar con los indios del Chaco boliviano, logró convencerlos de las ventajas de la vida civilizada, y fundó la Misión con sólo dos peones cristianos y con el Cacique Monocoidí y unas 40 o 50 familias que lo imitaron. En dos años se formó un núcleo importante, con Capilla y casa para la Misión y habitaciones para los indios, se acumularon herramientas de labor y una partida de unos 200 animales vacunos...y todo presagiaba un éxito lisonjero cuando incorporadamente desbordó el Río Pilcomayo, cubriendo con sus aguas las tierras más altas de sus márgenes, arrasó todo lo existente, casas, corrales, sembrados; dispersó la hacienda, y obligó a huir al Padre Misionero y sus indios, llevando con indecibles fatigas lo poco que pudieron salvar del desastre". ${ }^{32}$

Ante esta inundación producida en la zona del Pilcomayo, Fray Guido Depedri fue designado como representante del Convento de la Merced de Corrientes ante el Gobierno Nacional para conseguir la ampliación de la Misión con el aumento de 20.000 hectáreas en la zona del Pilcomayo. ${ }^{33}$ Esta segunda ubicación podía dar solución "a la mala calidad de la tierra", así como "a la gran cantidad de esteros existentes". En virtud de los propósitos que determinaron la creación de la Misión Franciscana, las distintas Comisiones Oficiales acordaron trazar los caminos y las rutas para asegurar la salida de los productos y las comunicaciones de la "Colonia Indígena". ${ }^{34}$

El 24 de setiembre de 1902, Fray Guido Depedri solicitó al Ministerio de Agricultura el cambio del lugar de la Misión para facilitar el trabajo del Misionero Fray Terencio Marcucci, el responsable de la Misión del Pilcomayo. ${ }^{35}$ El 15 de noviembre de 1902, el 
Presidente Julio Argentino Roca decretó la ampliación de 60.000 hectáreas de la concesión otorgada a los franciscanos "para un mayor desarrollo de los indígenas formoseños". Siguiendo el decreto del 13 de julio de 1900 , sólo se adjuntó un subsidio de $\$ 5000 \mathrm{~m} / \mathrm{n}^{36}$

El Jefe de la Dirección General de Tierras y Colonias del Ministerio de Agricultura se hizo cargo del proyecto de modificar el sitio de la Misión. Antonio J. Carballo volvió a dibujar un croquis en la ciudad de Buenos Aires: el 15 de noviembre de 1902 registró la primera ubicación de 40.000 hectáreas en medio del río Pilcomayo, así como la ampliación de 20.000 hectáreas hacia la zona sur, en la zona "del Chajá" o de "multitud de Chajá" del Tacaaglé. En este caso podemos observar que Carballo dejó de registrar la antigua concesión paraguaya de Elisa Lynch (Imagen № 3). ${ }^{37}$

Imagen $\mathrm{N}^{\circ} 3$

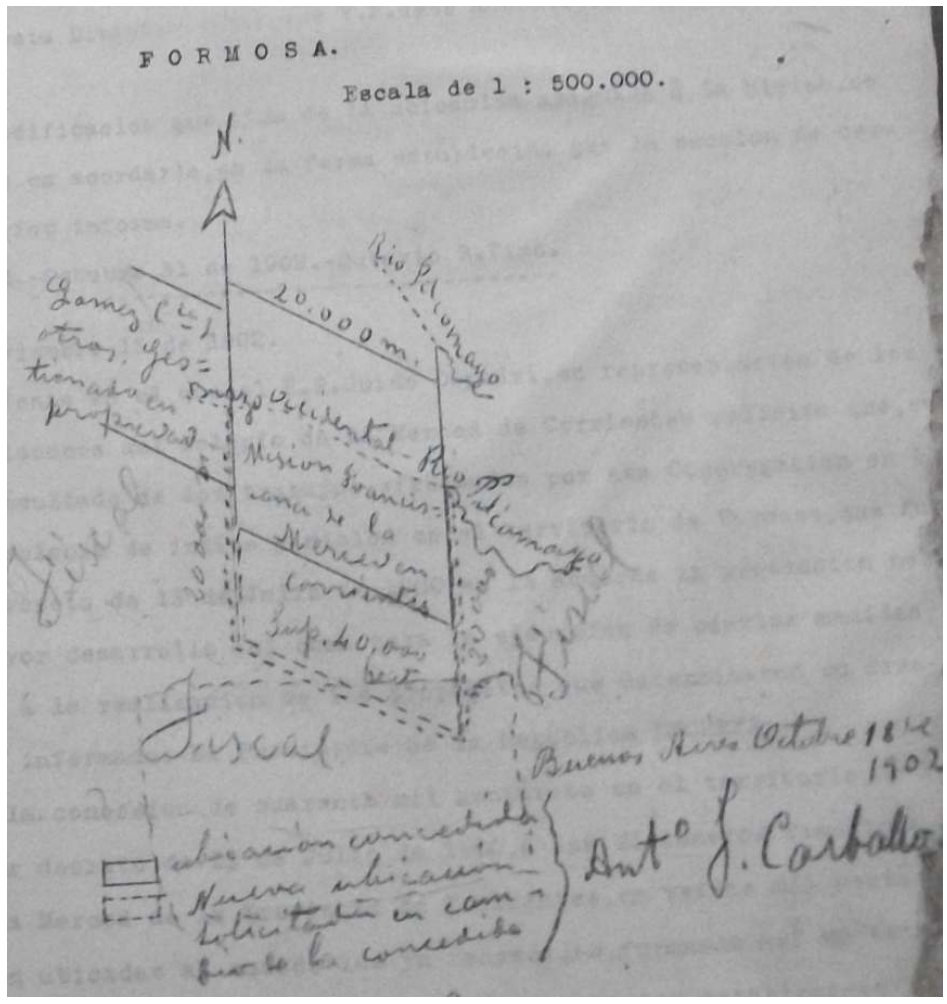

BACSC, Caja 47: "Carpeta Tacaaglé", Croquis del Jefe de la División de Tierra y Colonia, Antonio J. Carballo, al Ministro de Agricultura, Buenos Aires, 18 de octubre de 1902 (N² 2851-M-1902, D. T. C. No 2354.1902, No 862)

El Misionero Fray Marcucci cayó enfermó, y se trasladó entonces con gran dificultad al nuevo asiento de la Misión en el paraje de la zona alta llamado Tacaaglé, que gozaba de buenas tierras para el cultivo de maíz, porotos, maní, arroz, batatas, mandioca, caña dulce, alfalfa... Paralelamente hizo levantar un puente sobre el riacho Ñocacaldá, en el camino a la Misión abandonada, y abrió otro camino para ir hacia el río Pilcomayo. Años después de esta inundación y traslado, Fray Pedro Iturralde escribió que el Misionero Fray Marcucci se vio obligado a recorrer un trayecto de 4 a 5 leguas de campo que estaban cubiertos de agua. 


\section{Imagen $\mathrm{N}^{\circ} 4$}

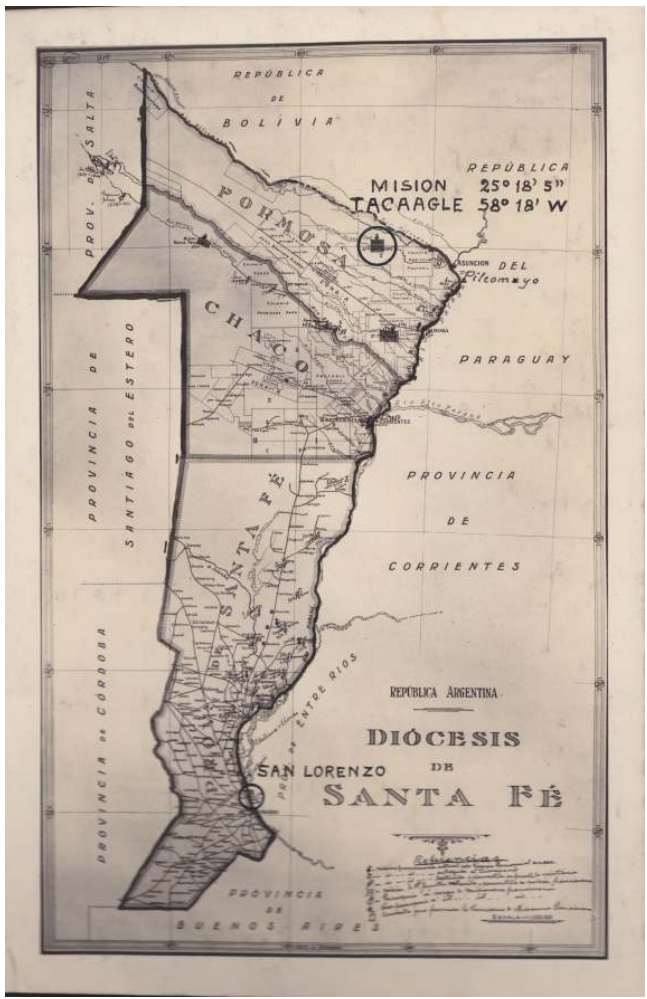

Mapa del año 1905, que indica las Misiones de la Diócesis de Santa Fe: Misión Nueva Pompeya (Territorio Nacional del Chaco), Misión Laishí (Territorio Nacional de Formosa), y especialmente Misión San Francisco Solano de Tacaaglé (Territorio Nacional de Formosa) en el Riacho Porteño de la zona del Río Pilcomayo, a $25^{\circ} 18^{\prime} 5^{\prime \prime}, 58^{\circ}$ 18’ W. El mapa también refleja la ubicación del Convento San Carlos Borromeo de San Lorenzo en la Provincia de Santa Fe.

Fuente: Archivo y Biblioteca del Convento San Carlos Borromeo de San Lorenzo en la Provincia de Santa Fe. 


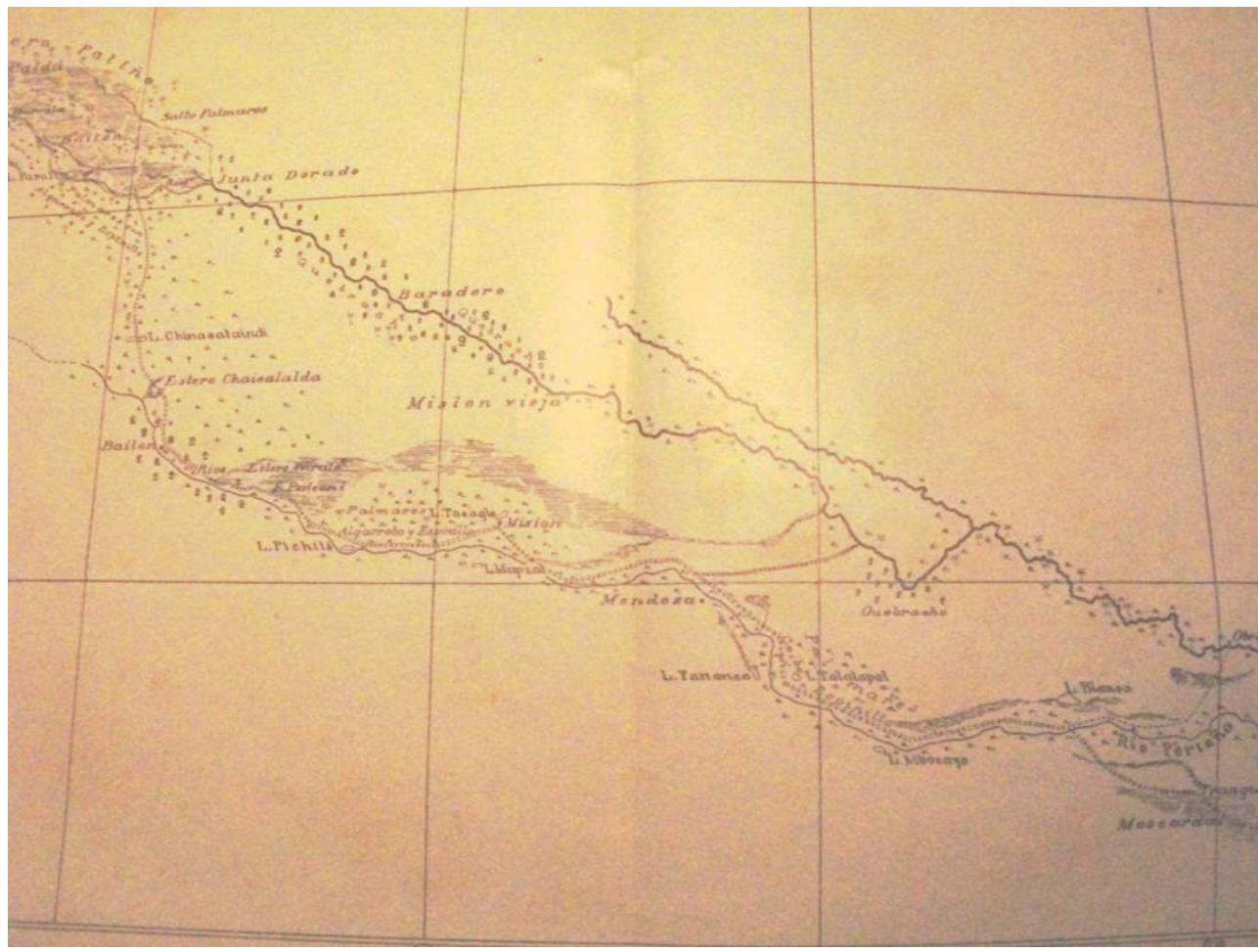

Expedición 1905, Río Pilcomayo, Croquis de Misión Vieja y Misión Nueva, con Itinerario recorrido por el Convoy Terrestre. El 15 de noviembre de 1902 se amplió la primera ubicación, sumando 20.000 hectáreas a la superficie acordada en 1900. Según datos aproximativos: escala 1:600000; referencias: Camino, Esteros, Quebracho, Tolderías.

BACSC, Caja 47: Carpeta Tacaaglé, carta de Fray Pedro Iturralde al Ministerio de Agricultura, Buenos Aires, 20 de mayo de 1932.

Soportó privaciones, "con peligro de la vida y amargado por el dolor de ver frustrados tantos trabajos, esperanzas e ilusiones de un éxito halagüeño". Fue el primer fracaso de la empobrecida Misión, pero no por culpa de los franciscanos, sino por el hábitat de la zona chaqueña en la frontera con Paraguay; en palabras de Fray Iturralde:

“El Misionero ve malogrados sus trabajos, destruida su Misión y agobiado bajo el peso de tanta desgracia, emigra en una canoa endeble, y después de navegar con no poco peligro, aquel lago inmenso de más de 20 kilómetros de anchura, llega a una altura y allí levanta su toldo, y comienza a rehacer su obra, tan lastimosamente interrumpida. Reúne sus indios, cultiva la tierra, construye edificios, corrales, cercados, etc. La Misión prospera y se mantiene con los productos de la hacienda, cuyo número aumenta, y con los de la chacra que se extiende a más de 100 hectáreas...los indios aprenden agricultura práctica y se preparan a trabajar por su cuenta". 38

Años después el Ministro de Agricultura reconoció ante la Dirección General de Tierras y Colonias que "la civilización del indio no es obra de un día", y por ello era necesario legitimar la venta de madera de quebracho sobrante de la Misión San Francisco Solano "para obtener fondos". ${ }^{39}$ Recién en setiembre de 1909, la Dirección General de Tierras y Colonias hizo llegar al Ministro de Agricultura, Pedro Ezcurra, la solicitud de los Misioneros de vender maderas del Pilcomayo. ${ }^{40}$ El Gobierno Nacional nunca respondió a este reclamo, y en octubre de 1910 la Dirección de Tierras y Colonias estableció el inicio 
de la Inspección de las Colonias Indígenas, en especial la investigación sobre la Misión de Tacaaglé. ${ }^{41}$

\section{4.- El Ferrocarril de Formosa a Embarcación (F.C.F.E.) y la Misión Indígena Franciscana de Tacaaglé}

En 1914 el Comisario y Superior de los Misioneros Franciscanos le hizo llegar al entonces Ministro del Interior, Miguel S. Ortiz, el informe sobre la Misión de San Francisco Solano de Tacaaglé, la cual se encontraba en ambas márgenes del brazo sur del río Pilcomayo. Fray Rafael Gobelli solicitó entonces la zona en la margen izquierda del riacho Porteño, y reconoció que la Misión "progresó poco y deficientemente, por causas diversas y complejas, una de ellas ha sido las malas condiciones del terreno adjudicado". Finalmente, señaló que una nueva concesión para la Misión de Tacaaglé podía garantizar su tarea civilizadora ya que "los mismos indios se afianzarán más en sus propósitos al saber que pueden estar seguros de la posesión actual y propiedad futura de sus terrenos". Siguiendo las sugerencias del Comisario Superior Fray Gobelli, el Gobierno tendría siempre en sus manos dejar sin efecto la concesión de las tierras si los responsables observaban que los propios Misioneros cometían errores en la "radicación y perseverancia de los indios". En consecuencia, debido a las grandes inundaciones y desbordes del río Pilcomayo, era indispensable cambiar la ubicación del terreno concedido por los decretos del 13 de Julio de 1900 y del 15 de noviembre de $1902 .{ }^{42}$

La solicitud se centró en el terreno fiscal libre, “por ser estas últimas tierras”, a juicio del representante de los Misioneros Franciscanos, "las más indicadas para la radicación del indio por lo apropiadas que son para los trabajos agrícolas". ${ }^{43}$ Fray Rafael Gobelli solicitó entonces que adjudicaran a la Misión Indígena una tierra apta para el logro de los fines de su fundación:

"Cambiar el terreno concedido a la Misión de San Francisco Solano de Tacaaglé, adjudicándole los lotes números 3 y 4 de la Sección II, que fueron mensurados por el Ingeniero D. Miguel Olmos, que en conjunto constan de 20.000 hectáreas y una superficie igual al Norte de dichos dos lotes y colindando con ellos". ${ }^{44}$

Siguiendo esta solicitud, el Gobierno Argentino debía aceptar el tercer traslado y, en especial, la reducción de 60.000 a 40.000 hectáreas, estas últimas ubicadas entre las 20.000 hectáreas de los lotes 3 y 4 de la Sección II de la zona de influencia del Ferrocarril de Formosa a Embarcación (F.C.F.E.), y la otra mitad establecida al norte de los lotes colindantes, comprendiendo parte del terreno de la Misión Indígena. Esta propuesta incluyó un interesante croquis elaborado en Buenos Aires por José S. Sarhy, responsable de la División Geodesia, quien señaló el terreno concedido en la zona de influencia del F.C.F.E., para "establecer allí la reducción de indios". Sarhy se centró primero en los decretos del 13 de julio de 1900 (40.000 hectáreas) y del 15 de noviembre de 1902 (60.000 hectáreas), y luego registró el cambio de ubicación propuesto por la Misión San Francisco Solano de Tacagalé (Tacaaglé) en el año 1914 (expediente 85.K915). En síntesis, el Ministerio de Agricultura aceptó este cambio el 19 de abril de 1915, mientras Sarhy volvió a diseñar un croquis con las 40.000 hectáreas definitivas "para la fundación de una Misión y Colonia de indios", en la "zona de influencia del Ferrocarril de Formosa a Embarcación" (Imagen № 4). ${ }^{45}$ 


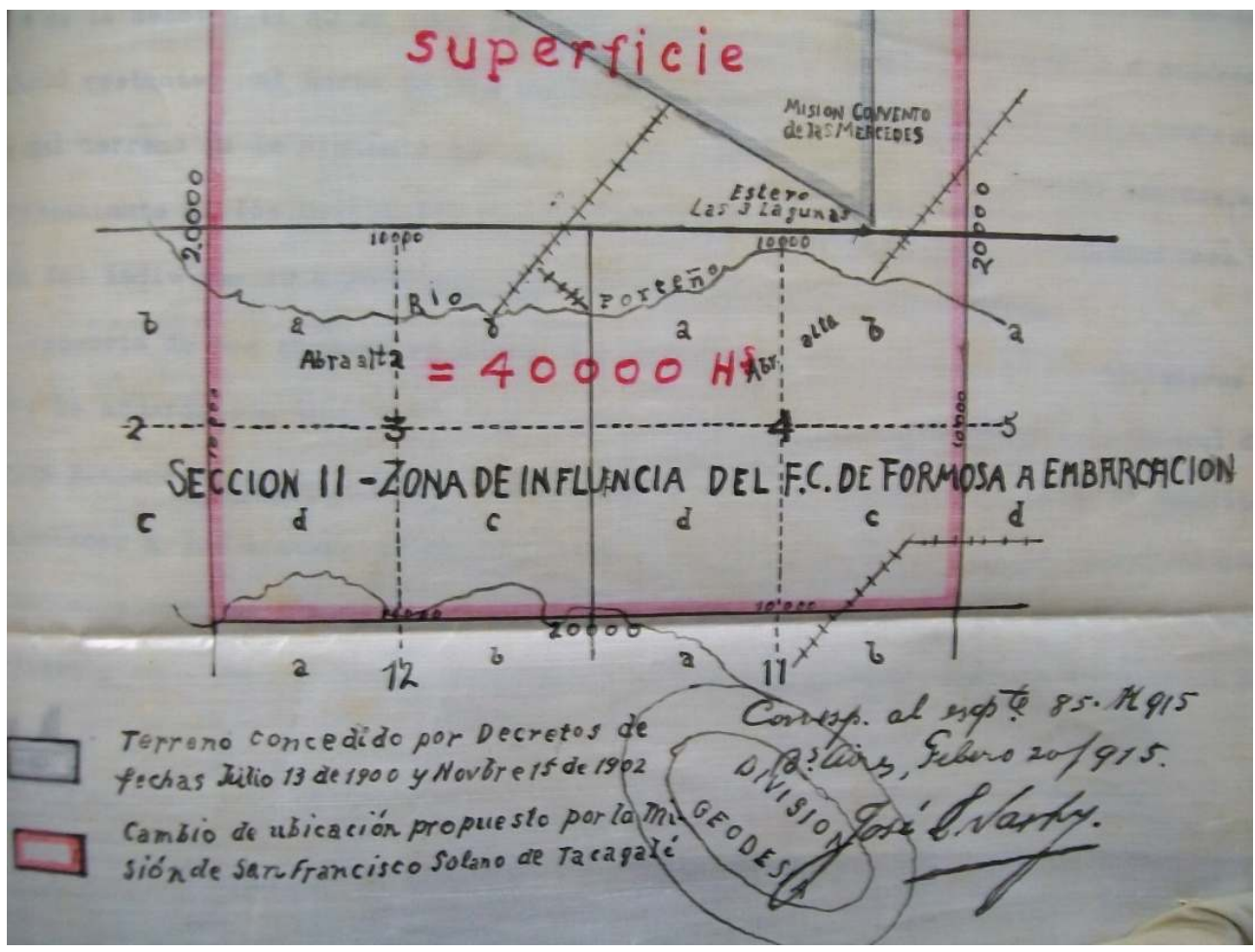

BACSC, Caja 47: Carpeta Tacaaglé, Croquis de José S. Sarhy para ampliar el territorio de la Misión de Tacaaglé e incorporar indígenas pilagás, 20 de febrero de 1915.

Tengamos en cuenta que por Ley $\mathrm{N}^{\circ} 5.559$ de Fomento de los Territorios Nacionales de la República Argentina (Bucciarelli y Jensen, 2008), se autorizó la construcción y explotación de un ferrocarril que se desplazase desde la Capital de Formosa hacia Embarcación. El acuerdo general de Ministros le concedió poder al ingeniero Guillermo N. Juárez para dar inicio a la construcción del F.C.F.E. el 16 de setiembre de 1908. La sección de Formosa a Pirané se cumplió el 22 de setiembre de 1910 a través de 100 kilómetros de longitud, mientras que la sección de Pirané a Las Lomitas se inauguró el 20 de julio de 1915 gracias a la construcción del ferrocarril en los 197 kilómetros restantes. ${ }^{46}$ En ese preciso momento se decidió elaborar un interesante croquis sobre la concesión del terreno para la Misión Franciscana en la zona del riacho El Porteño, al costado de los hermanos Lotto. En dicho croquis se observa, en primer lugar, la ubicación de las hectáreas otorgadas a los indígenas; en segundo lugar, la zona de las chacras de instrucción de los tobas y pilagás ingresados a la Misión después de 1914; y, en tercer lugar, el puente, el potrero y la zona del Estero las Tres Lagunas (Imagen № 5). 


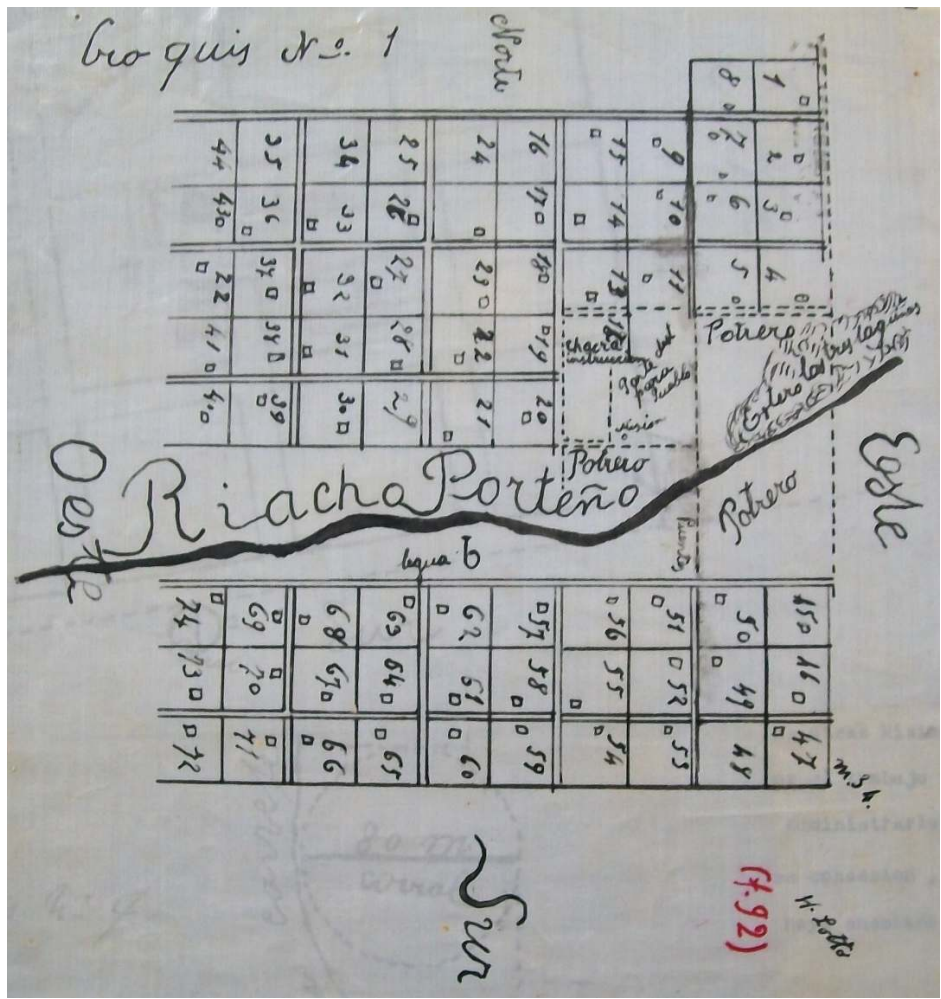

BACSC, Caja 47: Carpeta Tacaaglé, Croquis $N^{\circ} 1$ en el riacho El Porteño, reubicación de la Misión de Tacaaglé hacia 1916, al costado de los Hermanos Lotto.

En ese contexto, la administración de los Ferrocarriles del Estado tomó posesión de la línea del Ferrocarril de Formosa a Embarcación (F.C.F.E.) en 1915, y por ello el Ministerio de Agricultura reconoció que la superficie ocupada por entonces por la Misión Indígena San Francisco Solano "no podrá prosperar la reducción de indios citados, que si bien es cierto, como lo informa la Dirección General de Tierras y Colonias, que la tierra fiscal necesaria para formar esa superficie de 40.000 hectáreas con la parte sur de la concesión acordada, está regida por la Ley № 5.559, que prohíbe la enajenación de estas tierras". ${ }^{47}$ En este último traslado, se elaboraron dos pequeños esquemas sobre las antiguas tierras fiscales que rodeaban precisamente a la Misión de Tacaaglé. En primer lugar, el croquis que incluye la renuncia de 20.000 hectáreas por parte de la Misión; la nueva zona arrendada a Luis Catáneo; la ubicación del rodeo y de la Misión; así como el espacio arrendado por Irenarco Candia en la antigua zona Nococolda otorgada a los franciscanos, y cercana al Estero Bacaldá (Imagen № 6). En segundo lugar, el croquis definitivo que quedó en manos del por entonces Prefecto de Misiones, Fray Pedro Iturralde, apoyando la recepción de los lotes 3 y 4 de la zona sur del riacho El Porteño para los indígenas tobas y pilagás de la zona chaqueña formoseña (Imagen № 7). 
Imagen $\mathrm{N}^{\circ} 8$

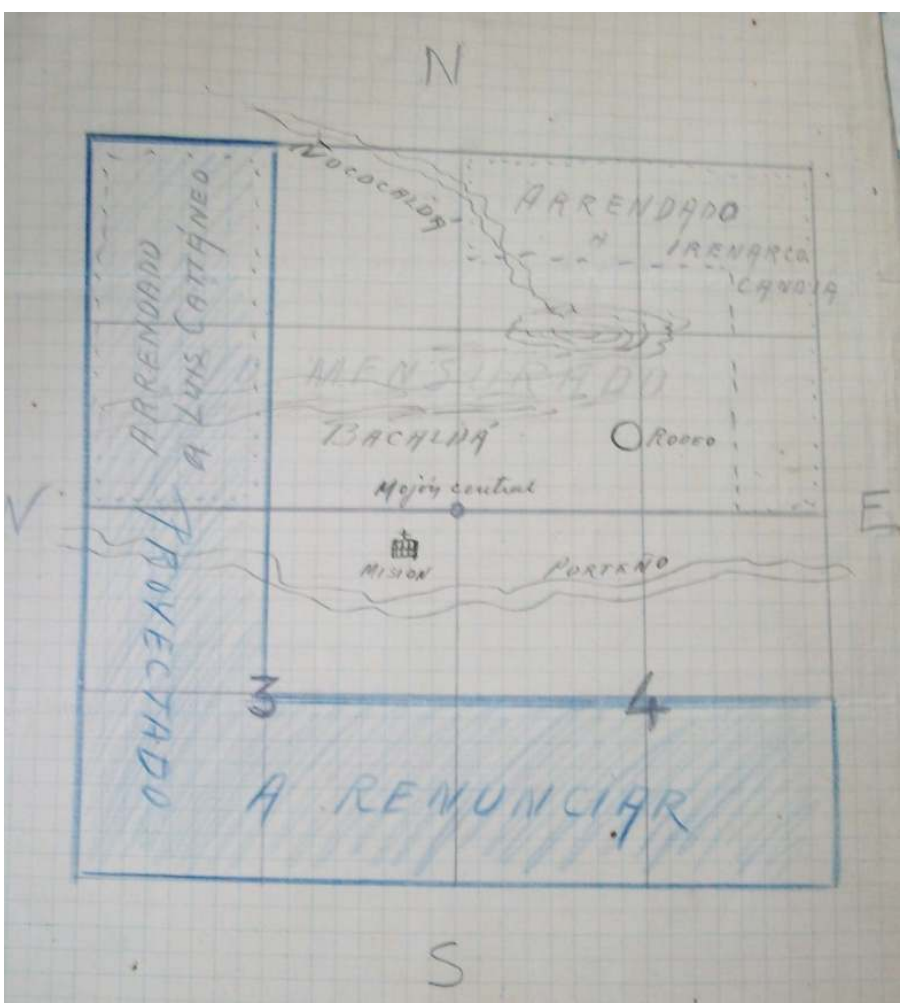

BACSC, Caja 47: Carpeta Tacaaglé, Proyectado al renunciar 20.000 hectáreas de la zona del riacho El Porteño, y zona de Nococolda (Ñococaldá), 1915. 


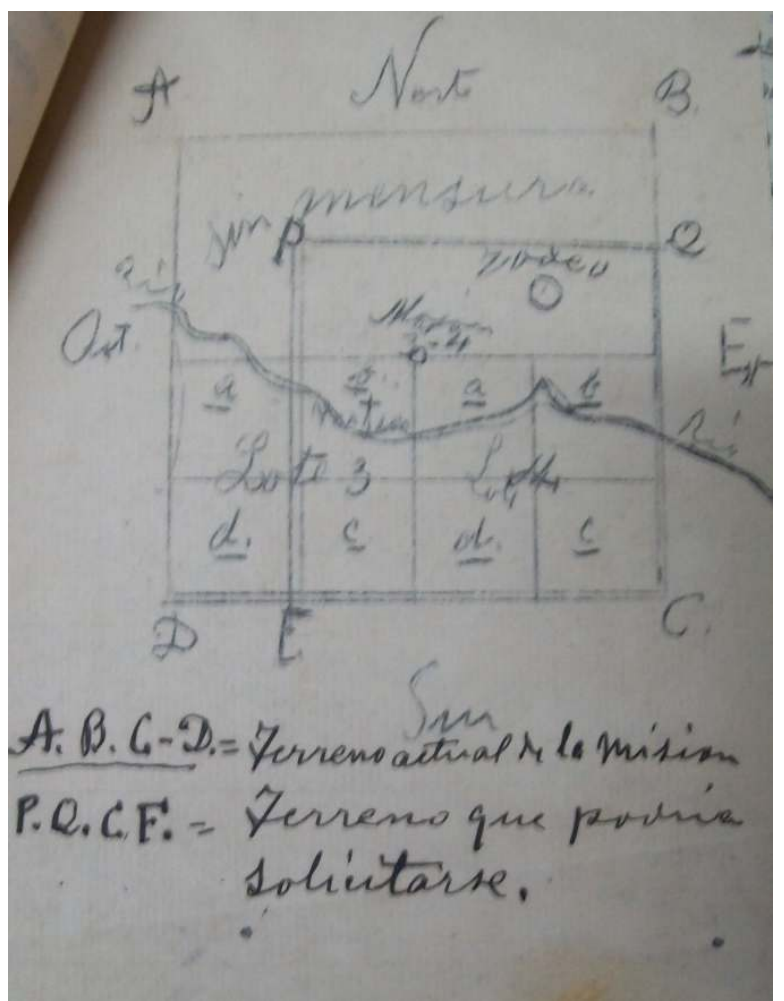

BACSC, Caja 47: Carpeta Tacaaglé, Croquis de Fray Pedro Iturralde, riacho El Porteño, reubicación Misión de Tacaaglé, 3 de enero de 1917.

Desde entonces, Fray José Zurflüh se integró a la Misión San Francisco Solano como Misionero Principal después de acompañar a Fray Buenaventura Giuliani en la Misión formoseña de Laishí (Dalla-Corte y Vázquez, 2011). En julio de 1925 escribió una intensa carta dirigida a los Frailes Antonio Pighín y Joaquín María Ducca, en la que se refirió al terrible incendio que sufrió la Misión de Tacaaglé en el riacho El Porteño, es decir, en la zona de ubicación del último traslado de los indígenas tobas y pilagás. Este acontecimiento fortaleció las intensas críticas que sufría la Misión desde el año 1916, cuando el Gobernador de Formosa decidió inspeccionar por primera vez los resultados franciscanos en Tacaaglé. En palabras de Zurflüh:

"Nos sucedió una desgracia que casi termina con la casa de la Misión. En la madrugada del 25 de junio pasado, un incendio nos destruyó totalmente la proveeduría o almacén, quemándose todos los comestibles, herramientas, géneros, ropa y muchas cosas más que estaban allí como depósito. Quedamos sin nada. A la una de la mañana me desperté sobresaltado, y, como acostumbro a dormir con puerta y ventana abiertas, tuve la suerte de advertir el resplandor rojizo que iluminaba mi cuarto y comprendí que había incendio en la casa. Salto despavorido, llamo al Padre Pablo [Rossi], comencé a dar alaridos para llamar la atención de los indios, disparé armas de fuego, corriendo y buscando baldes. El P. Pablo tocó la campana, y comenzó a desalojar el algodón de un galpón grande contiguo al almacén y yo sobre el techo echando agua, procurando detener el fuego en unas tejas de palma, hasta que llegaron los indios y con hachas comenzamos a derivar los locales vecinos, y así conseguimos localizar el fuego, que ardió hasta medio día. Fue un momento de susto y desesperación, gritos, corridas, caídas. Con los hábitos rotos y las caras ennegrecidas, íbamos los dos acudiendo a todas partes, distribuyendo y ordenando el trabajo de los indios, a quienes debemos haberse salvado el resto de la 
Casa de la Misión. Mi primera impresión fue que todo estaba perdido, porque las llamas envolvían todo el edificio y se elevaban espantosamente en el aire y lamían ya los galpones contiguos. En fin, Dios nos ha sometido a una dura prueba, pero no nos ha ahogado...como merecemos". ${ }^{48}$

El 13 de junio de 1927 el Poder Ejecutivo permitió la licitación del F.C.F.E. que ya había cubierto $405 \mathrm{~km}$. El tramo en línea había alcanzado $360 \mathrm{~km}$, es decir, la longitud que por entonces se consideraba la más larga del mundo. Pocos años después, en 1931, se unieron en Embarcación las líneas del F.C.F.E. y del Ferrocarril Central Norte Argentino (F.C.N.A.), y el primero pasó a formar parte del segundo precisamente en el momento en que Fray Pedro Iturralde dirigió al Ministerio de Agricultura una intensa carta en defensa de la Misión San Francisco Solano de Tacaaglé. Con la intención de frenar la caducidad de la Misión Indígena, el antiguo Prefecto de Misiones acusó a los empresarios y a los pobladores, en su mayoría extranjeros (Beck, 2001), que pretendían controlar el territorio de los indígenas tobas y pilagás para apropiarse de sus tierras y aprovechar la llegada del F.C.F.E. Para Fray Iturralde, la zona chaqueña formoseña, hasta entonces en manos de los aborígenes y de los Misioneros Franciscanos, terminaría cayendo en manos empresariales. Sin vergüenza alguna, Fray Iturralde afirmó que los franciscanos habían defendido los terrenos de las márgenes del río Pilcomayo y del río Porteño contra la República del Paraguay. Si el Poder Ejecutivo dejaba en manos privadas ese importante territorio nacional, el motivo no era otro que el éxito del F.C.F.E.

Frente a esto, Fray Iturralde se preguntó por qué se planteaba la expulsión de los Misioneros Franciscanos, pese a que habían cumplido con la función de otorgar "amparo y refugio" a los indígenas, frenando así "el desastre en que se hallaban". Para Fray Iturralde, todo esto no era otra cosa que una "injusticia irritante" que despojaba a los aborígenes, ciudadanos argentinos, de sus tierras y de sus bienes formoseños. La finalidad, según él, era más bien ilegítima, ya que también afectaba a los propios colonos argentinos que estaban siendo desplazados por los empresarios extranjeros. " $i$ Y por qué?", se preguntó Fray Iturralde. Ante ello contestó: "para dar cabida a pobladores extranjeros, algunos de los cuales viven en su propio país, mientras en el Chaco sólo tienen sus haciendas". Fue entonces cuando también reconoció que gran parte de los niños y niñas nacidos en la zona formoseña de la República Argentina eran registrados en el Paraguay para conservar esa nacionalidad frente a las disposiciones impuestas por el gobierno argentino:

"Los pobladores honestos y de buena fe avanzan hasta ellos, los pueblos, introducen hacienda y capitales propios y fomentan el progreso de la región, como lo hacían y lo hacen aún los viajeros a que acabo de referirme, pero estos no pretenden apoderarse de las tierras de los indios de la Misión de Tacaaglé), ni intentan perjudicar a ésta, antes bien la favorecen...saben que el indio, mientras pertenece a la Misión...es una garantía para los pobladores, mientras los montaraces y nómadas son una amenaza y un peligro. No son, estoy convencido de ello, estos pobladores honestos, los que han influido en el ánima de la Comisión y de las Subcomisiones Investigadoras, para lograr la caducidad de la Misión. Son los otros, los que llegan a poblar con más miedo que hacienda y quieren establecerse donde no hay peligro, pero sí obras, elementos, alambrados, tierras aradas, frutos de los sudores y fatigas de los pobres indios, que pueden utilizar en beneficio propio. ¿Por qué no fueron allá, cuando los indios eran nómadas y merodeadores? ¿Por qué, ahora mismo, no avanzan como los buenos pobladores que he mencionado y van a ocupar los campos ocupados por los Pilagás, Sotegaité, etc.? Es que les resultaría más cómodo que los Misioneros, desposeídos de su actual Misión, fueran a fundar otra entre los salvajes, 
y una vez domesticados éstos, ir ellos á otros como ellos, a suplantarlos; y que los

Misioneros avanzasen más aún, para repetir ellos la misma maniobra". ${ }^{49}$ convirtió en un espacio de frontera (González, 1890) en el cual se aplicaron diversas estrategias para incorporar a las sociedades indígenas originarias definida como "salvajes y bárbaras". Posteriormente el Estado Nacional Argentino formalizó la delimitación fronteriza con Paraguay con un interés económico concreto (Girbal-Blacha, 1993, 1995, 2011), y un buen número de indígenas guaycurúes quedó en lo que se define como "fronteras interiores" (Rodríguez Mir, 2007; Zarrilli, 2004). Sobre la base de ocupación y nacionalización de esta supuesta "desértica" zona formoseña (Trinchero, 2000; Teruel, Lacarrieu, Jerez, 2002), desde finales del siglo XIX el gobierno nacional entró en contacto con los franciscanos para promover la fundación de Misiones Indígenas. Precisamente Tacaaglé formó parte de este proyecto nacional impulsado por los grupos dirigentes en el ámbito estatal y regional. Dicho contexto justificó la creación de una Misión Indígena en manos franciscanas, la cual quedó ubicada en la zona del río Pilcomayo, es decir, en el espacio de lucha entre Paraguay, Bolivia y la propia Argentina hasta el fin del terrible conflicto bélico representado por la Guerra del Chaco (Dalla-Corte, 2010).

Desde inicios del siglo XX, la Misión bautizada como Tacaaglé sufrió inundaciones, traslados e incendios. Esta historia no es sencillamente una descripción a priori, como tantas, en las que los principios fundamentales suelen ir del brazo de enormes contradicciones, sino de algo más sutil y vivo que escapa a las acostumbradas informaciones de los estudios más técnicos, y que en muchos casos es sólo dable reconstituir con ayuda de la imaginación. Las representaciones fabricadas sobre los indígenas tobas y pilagás de la Misión de Tacaaglé, provocaron cambios significativos y

Corpus, Vol 3, No 1 | 2013 
contradictorios entre las gestiones institucionales y religiosas, pero no debemos olvidar que la propia transformación económica del territorio formoseño, ligada a la creciente visibilidad de los responsables de los establecimientos productivos, fue transformando las propias relaciones sociales.

El proyecto impulsado en el Territorio Nacional de Formosa, este último reconocido muy tardíamente como parte de la República Argentina, incluyó involuntariamente una mayoritaria presencia paraguaya en los nuevos asentamientos productivos. Los grupos dirigentes siguieron un camino singular: acompañaron la integración indígena en la Misión de Tacaaglé para garantizar su nacionalidad argentina, pero también estimularon su desaparición en el marco de un progresivo control territorial gracias al ferrocarril. La excusa que utilizó el Estado para justificar sus críticas dirigidas a la labor de los franciscanos, fue siempre el negativo efecto de los traslados de las "tribus indígenas" que impedían su control disciplinario. La Misión Franciscana del riacho El Porteño dejó de estar en manos franciscanas desde el momento en que el Territorio Nacional de Formosa se convirtió en Provincia durante la Presidencia de Juan Domingo Perón (Ruffini, 2005, 2010). Poco después, la localidad de la Misión de Tacaaglé se hizo cargo de la casa parroquial creada por los Misioneros Franciscanos en el Departamento Pilagás. ${ }^{51}$

Frente a la exigua historiografía sobre los tobas y pilagás formoseños, es importante rescatar la documentación conservada por los franciscanos, la cual permite reconstruir las relaciones tejidas entre los grupos dirigentes y empresariales, los Misioneros y los "colonos indígenas". También ofrece interesantes reflexiones sobre el proyecto expansionista debatido entre los paraguayos y los argentinos responsables de los diversos establecimientos productivos del Territorio Nacional de Formosa. Finalmente, ante los indígenas "salvajes", la Misión de Tacaaglé fue la salida más digna y honrosa en el marco del régimen misional: si bien la incorporación de los indígenas al proyecto nacional se llevó a cabo a través de diversos mecanismos coactivos -entre ellos precisamente el religioso-, la posible expulsión de los Misioneros y la dispersión de los llamados "colonos indígenas" alimentó el conflicto desatado entre el Poder Ejecutivo, el Gobernador del Territorio Nacional de Formosa, y la Orden Franciscana. La estrategia no fue sólo exigir el abandono misional para reforzar la médula empresarial, sino que acompañó históricamente el avance ferroviario para consolidar la supremacía del poder mercantil.

\section{BIBLIOGRAFÍA}

Arias Bucciarelli, Mario, Jensen, Silvina (2008). La historiografía de los Territorios Nacionales: un campo en construcción. Anuario del Centro de Estudios Históricos Prof. Carlos S. A. Segreti, Año 8, $\mathrm{N}^{\circ} 8$, pp. 183-200.

Beck, Hugo Humberto (2001). Inmigrantes europeos en el Chaco: transición del pluralismo al crisol. Resistencia, Cuadernos de Geohistoria Regional (№ 39).

Borrini, Héctor R. (1997). Poblamiento y colonización en el Chaco paraguayo (1850-1990). Resistencia, Cuadernos de Geohistoria Regional (№ 32). 
Brezzo, Liliana y Figallo, Beatriz (1999). La Argentina y el Paraguay, de la guerra a la integración. Imagen histórica y relaciones internacionales. Rosario: Pontificia Universidad Católica Argentina.

Dalla-Corte Caballero, Gabriela (2009). Lealtades firmes. Redes de sociabilidad y empresas: la Carlos Casado S. A. entre la Argentina y el Chaco paraguayo (1860-1940). Madrid: Consejo Superior de Investigaciones Científicas (CSIC).

Dalla-Corte Caballero, Gabriela (2010). La Guerra del Chaco, Ciudadanía, Estado y Nación en el siglo XX. La crónica fotográfica de Carlos de Sanctis. Rosario: Prohistoria Ediciones y TEIAA/UB (reproducido en Asunción, Editorial Intercontinental, 2010).

Dalla-Corte Caballero, Gabriela (2012 a). Empresas y tierras de Carlos Casado en el Chaco Paraguayo. Historias, negocios y guerras (1860-1940). Asunción: Intercontinental Editora.

Dalla-Corte Caballero, Gabriela (2012 b). Los misioneros franciscanos Pedro Iturralde y Buenaventura Giuliani en la Misión Indígena de Laishí de Formosa (Argentina, primera mitad del siglo XX). Revista Estudios Franciscanos, Vol. 113, no 453: 193-224.

Dalla-Corte Caballero, Gabriela y Vázquez Recalde, Fabricio (2011). La conquista y ocupación de la frontera del Chaco entre Argentina y Paraguay. Los indígenas tobas y pilagás y el mundo religioso en la Misión Tacaaglé del Río Pilcomayo (1900-1950). Barcelona: Publicacions de la Universitat de Barcelona.

Girbal-Blacha, Noemí M. (1993). Crisis obrajera, estrategias sectoriales y condiciones de trabajo en el Gran Chaco Argentino (1918-1930). Folia Histórica del Nordeste, № 11: 5-30.

Girbal-Blacha, Noemí M. (1995). Reflexiones sobre la historia rural y la situación agraria de las economías extra-pampeanas. El caso del Gran Chaco Argentino y la explotación forestal (1895-1930), en: Bjerg, Mónica y Reguera, Andrea (comp.). Problemas de la historia agraria, Nuevos debates y perspectivas de investigación. Tandil: IEHS.

Girbal-Blacha, Noemí M. (2011). Vivir en los márgenes. Estado, políticas públicas y conflictos sociales. El Gran Chaco Argentino en la primera mitad del siglo XX. Rosario: Prohistoria Ediciones.

González, Melitón (1890). Gran Chaco Argentino (obra dedicada al Instituto Geográfico Argentino). Buenos Aires: Compañía Sud-Americana de Billetes de Banco.

Gordillo, Gastón (2001). Un río tan salvaje e indómito como el indio toba: una historia antropológica de la frontera del Pilcomayo. Desarrollo Económico, № 162, vol. 41: 261-280.

Gordillo, Gastón (2005). Nosotros vamos a estar acá siempre. Historias Tobas. Buenos Aires: Biblos. Gordillo, Gastón (2007). En el Gran Chaco, Antropologías e Historias. Buenos Aires: Prometeo.

Lagos, Marcelo (2000). La cuestión indígena en el Estado y la sociedad nacional. Gran Chaco, 1870-1920. Jujuy: UNJu.

Lagos, Marcelo (2003). Estado y cuestión indígena. Gran Chaco, 1870-1920, en: Mandrini, Raúl y $\mathrm{Paz}$, Carlos (comp.). Las fronteras hispanocriollas del mundo indígena latinoamericano en los siglos XVIIIXIX. Un estudio comparativo (pp.429-460). Tandil: UNCPBA.

Quijada, Mónica (ed.) (2011). De los cacicazgos a la ciudadanía. Sistemas políticos en la frontera, Río de la Plata, siglos XVIII-XX. Berlín: Gebr. Mann Verlag.

Rodríguez Mir, Javier (2007). El Chaco argentino como región fronteriza. Límites territoriales, guerras y resistencia indígena (1865-1935). Hispania Nova: Revista de Historia Contemporánea, no 7.

Ruffini, Martha (2005). Peronismo, territorios nacionales y ciudadanía política. Algunas reflexiones en torno a la provincialización. Revista Avances del Cesor, Año V, № 5: 132-148. 
Ruffini, Martha (2010). Ecos del Centenario. La apertura de un espacio de deliberación para los Territorios Nacionales: la Primera Conferencia de Gobernadores (1913). Revista Pilquen, Sección Ciencias Sociales, Año XII, № 12, enero/junio.

Spota, Julio César (2009). Los fortines en la frontera chaqueña (1862-1884). Un enfoque desde la antropología histórica en relación con la teoría de las organizaciones. Memoria Americana, № 17, 1, Ciudad Autónoma de Buenos Aires, enero-junio.

Teruel, Ana (2005). Misiones, economía y sociedad. La frontera chaqueña del Noroeste Argentino en el siglo XIX. Buenos Aires: Universidad Nacional de Quilmes.

Teruel, Ana (2011). Chez les Matacos du Chaco argentin. Hommes et femmes dans un processus de colonisation tardive. Revista Clío, № 33, Vol. 1.

Teruel, Ana; Lacarrieu, Mónica; Jerez, Omar (comp.) (2002). Fronteras, ciudades y Estados. Córdoba, Alción Editora, t. I.

Trinchero, Hugo (2000). Los dominios del demonio. Civilización y barbarie en las fronteras de la Nación. El Chaco Central. Buenos Aires: Eudeba.

Wright, Pablo (2008). Ser-en-el-sueño: crónicas de historia y vida toba. Buenos Aires: Biblos.

Zarrilli, Adrián (2004). Transformación ecológica y precariedad económica en una economía marginal. El Gran Chaco argentino, 1890-1950, en: Barriera, Darío y Roldán, Diego (comp.). Territorios, espacios y sociedades, Agenda de problemas y tendencias de análisis (pp.79-100). Rosario: UNR.

\section{NOTAS}

1. Este trabajo forma parte del I+D+i HAR2012-34095, "El mundo latinoamericano como representación. La construcción de una representación política, social y cultural en América, 1880-1960" (P. García Jordán coord.); Taller de Estudios e Investigaciones Andino-Amazónicas (TEIAA), Universitat de Barcelona.

2. BACSC, Caja 47: “Copia Fiel”, Informe № 303, Exp. 2665-F-96, Informe de la Sección al Director, A. Margueirat, por solicitud del Gobernación de Formosa, Buenos Aires, 8 de febrero de 1897. También BACSC, Caja 47: “Copia Fiel”, Expediente № 2.100 agregado, Basualdo, Buenos Aires, 11 de febrero de 1897. BACSC, Caja 47: “Copia Fiel”, Agregación ordenada, C. Jurado, № 136, Buenos Aires, 12 de febrero de 1897.

3. BACSC, Caja 47, “Copia Fiel”, Expediente sobre fundación de una Misión por los Misioneros Franciscanos del Colegio de Nuestra Señora De la Merced de la Ciudad de Corrientes. Iniciado el año 1896. Registrado en el Ministerio de Interior con № 1.622-F-96. Id. En la Dirección de Tierras y Colonias № 2.665-F-96. Copiado del original el 13 de Febrero de 1912, por el Comisario General de Misiones Indígenas Franciscanas, Fray Pedro Iturralde. Seguido del Expediente № 2851-M-1902 sobre ampliación del terreno concedido por el acuerdo de 13 de julio de 1900, y con el Decreto de 15 de Noviembre de 1902, concediendo la ampliación. Nuevamente copiado por Fray Pedro Iturralde en diciembre de 1914.

4. BACSC, Caja 47, “Carpeta Tacaaglé", Expediente 93033-1929, Informes Oficiales desde Setiembre de 1918 hasta Noviembre de 1928. Dictámenes de las Oficinas de Tierras y Colonias, y Alegato, descontando los cargos de imputaciones que se hacen a los Misioneros Franciscanos (Fray Pedro Iturralde, junio de 1932).

5. BACSC, Caja 47: "Carpeta Tacaaglé", Carta enviada por Fray Pedro Iturralde, Buenos Aires, al Ministerio de Agricultura, Buenos Aires, 20 de mayo de 1932. 
6. BACSC, Lenguas Argentinas, Grupo Mataco-Mataguayo del Chaco, dialecto nocten, Pater Noster y apuntes por el padre Inocencio Massei (Orden Seráfica), con introducción y notas por Samuel A. Lafone Quevedo M.A., en Boletín del Instituto Geográfico Argentino, Tomo XVI, setiembre a diciembre de 1895, Cuadernos de 9 a 12 (incluye el Mapa Étnico de las tribus mataco-mataguayos del Gran Chaco, según carta del Padre Giomecchini y mapas del Padre Corrado, p. 345).

7. BACSC, Caja 47: “Copia Fiel”, Decreto del Presidente de la República, Julio Argentino Roca, por Acuerdo General de Ministros (Felipe Yofre, M. García Merou, A. Alcorta, E. Berduc, R. M. Fraga, Emilio Civit), Buenos Aires, 13 de julio de 1900.

8. BACSC, Caja 47: “Copia Fiel”, carta del Gobernador de Formosa, José María Uriburu (Secretario Juan Masferrer), al Ministro del Interior Don Norberto Quirno Costa, Buenos Aires, 18 de Agosto de 1896. Copia elevada por Norberto Quirno Costa, a la Subsecretaría de Tierras y Colonias (Dirección de Tierras y Colonias, O. S. Pico) del Ministerio de Justicia, Culto e Instrucción Pública, Buenos Aires, "para la resolución que estime conveniente, y avísese en respuesta", Buenos Aires, 29 de agosto de 1896.

9. BACSC, Caja 47: "Copia Fiel”, Informe de Ramón B. Castro, Sección de Tierras y Colonias, del Ministerio de Justicia, Culto e Instrucción Pública, Buenos Aires, № 759, Expediente № 2.100, a la Gobernación de Formosa, 2 de setiembre de 1896 (Director Basualdo, 12 de setiembre de 1896).

10. BACSC, Caja 47: "Copia Fiel”, Informe de A. Margueira, Sección Tierras y Colonias, a Gobernador de Formosa, Expediente 2100, F. 96, Informe № 129, Buenos Aires, 26 de setiembre de 1896.

11. BACSC, Caja 47: “Copia Fiel”, Informe de la Sección de Tierras, Colonias, Agricultura e Inmigración, al Director Basualdo, Buenos Aires, 29 de setiembre de 1896 (reenviado a Samuel Ballestrini, Buenos Aires, 19 de octubre de 1896).

12. BACSC, Caja 47: "Copia Fiel", Carta de los Padres Misioneros Franciscanos del Colegio Apostólico de Propaganda de la Merced de Corrientes, por intermedio de su Comisario General de Misioneros Franciscanos, Fray Salvador Mazza, a la Comisaría General de Misioneros Franciscanos, Buenos Aires, República Argentina, 18 de octubre de 1896 (Copia entregada al Gobernador de Formosa, Don José María Uriburu, Secretario Juan Masferrer).

13. BACSC, Caja 47: "Copia Fiel”, Informe del Gobernador de Formosa, José María Uriburu (Secretario Juan Masferrer), elevado con nota al Señor Ministro del Interior, Norberto Quirno Costa, Buenos Aires, 21 de octubre de 1896 (Pase a la Sub-Secretaría de Tierras y Colonias del Ministerio de Justicia, Culto e Instrucción Pública, para la resolución que estime conveniente, y avísese en respuesta, Norberto Quirno Costa, Buenos Aires, 27 de octubre de 1896). Este informe también se reproduce en BACSC, Caja 47: "Copia Fiel", Informe a la Dirección de Tierras y Colonias, O. S. Pico, Buenos Aires, 31 de octubre de 1896. BACSC, Caja 47: “Copia Fiel”, Informe a la Sección Tierras y Colonias, Director Basualdo, Buenos Aires, 3 de noviembre de 1896.

14. BACSC, Caja 47: "Copia Fiel”, Carta del Director de la Sección de Tierras y Colonias, Ramón B. Castro, Buenos Aires, 14 de enero de 1897.

15. BACSC, Caja 47: “Copia Fiel”, Expediente № 136 de la solicitud del 18 de agosto de 1896 del Gobernador del Territorio Nacional de Formosa, haciendo presente la conveniencia de crear una Colonia Indígena en las costas del río Bermejo a cargo de Misioneros, tomando por base las medidas dictadas por Acuerdo del Superior Gobierno de 23 de junio de 1896, relativas a la fundación de la Colonia Indígena que toma como plantel de población la tribu del cacique Valdivieso, zona río Pilcomayo, Director Basualdo, Secretario Carlos Jurado, Buenos Aires, 16 de febrero de 1897.

16. BACSC, Caja 47: "Copia Fiel”, Informe de Oficina Nacional de Geodesia, O. S. Pico, Expediente № 1.622, Buenos Aires, 18 de febrero de 1897.

17. BACSC, Caja 47: "Copia Fiel”, Gobernador de Formosa, José María Uriburu (Secretario Ricardo Freire), al Ministro de Justicia, Culto e Instrucción Pública, Buenos Aires, 2 de abril de 1898. También véase BACSC, Caja 47: “Copia Fiel”, Ministerio del Interior, 1622.F.96; D.T.2665.F.96; 
O.N.G. 226. F.96; № 175, Antonio Carballo, Buenos Aires, 5 de marzo de 1897. También BACSC, Caja 47: "Copia Fiel”, Informe de la Contaduría General de la Nación, O. S. Pico, Buenos Aires, 9 de marzo de 1897, y Francisco Vives, 26 de marzo de 1897. BACSC, Caja 47: "Copia Fiel”, Paso a la Dirección de Tierras y Colonias, Buenos Aires, 3 de noviembre de 1898. BACSC, Caja 47: "Copia Fiel”, Informe Geodesia, Antonio J. Carballo, Buenos Aires, 29 de noviembre de 1898.

18. BACSC, Caja 47: “Copia Fiel”, Gobernador de Formosa, José María Uriburu (y Ricardo Freire, secretario), al Ministro de Agricultura, 7 de febrero de 1899, sobre la resolución del Ministerio de Justicia, Culto e Instrucción Pública (Sub-Secretaría de Tierras, Colonias, Agricultura e Inmigración).

19. BACSC, Caja 47: "Copia Fiel", Fray Salvador Mazza, Comisario General de Misioneros Franciscanos, y secretario Fray Enrique Biagini, Calle Piedad 3461 de Buenos Aires, 4 de noviembre de 1899, a Emilio Civit, Ministro de Agricultura y Comercio, Buenos Aires, República Argentina.

20. BACSC, Caja 47: “Copia Fiel”, Informe de la Dirección de Tierras y Colonias, Buenos Aires, 14 de noviembre de 1899.

21. BACSC, Caja 47: "Copia Fiel”, Resolución de aceptación agregado al Expediente F. 1622/96, A. Etcheverría, Buenos Aires, 10 de noviembre de 1899.

22. BACSC, Caja 47: "Copia Fiel", Autorización del Fray Gabriel Grotti, Prefecto de Misiones de la Residencia Ordinaria de Formosa, a Fray Terencio Marcucci, Formosa, 30 de abril de 1900.

23. BACSC, Caja 47: “Copia Fiel”, Fray Terencio Marcucci, Misionero Franciscano del Colegio de la Merced de Corrientes, en nombre y representación del Prefecto de Misiones de dicho Colegio, al Señor Ministro de Agricultura, Martín García Merou, Buenos Aires, 9 de mayo de 1900.

24. BACSC, Caja 47: “Copia Fiel”, Informe del Oficial Mayor B. Decoud, a la Dirección de Tierras y Colonias, Buenos Aires, 10 de mayo de 1900, en atención a la ubicación solicitada.

25. BACSC, Caja 47: “Copia Fiel”, Informe de la División de Geodesia, P. Piñeiro Sorondo, Buenos Aires, № 488, 12 de mayo de 1900.

26. BACSC, Caja 47: Carpeta Tacaaglé y “Copia Fiel” № 523, Octavio S. Pico, Informe y dos croquis de Antonio J. Carballo, Buenos Aires, 6 de junio de 1900.

27. BACSC, Caja 47: "Copia Fiel", Nota de Antonio J. Carballo, Ministerio de Agricultura, 2964.M.900- Dirección de Tierras y Colonias, 2391.M.900, № 1128, 19 de octubre de 1900, Buenos Aires.

28. BACSC, Caja 47: “Copia Fiel”, Decreto del Presidente de la República, Juan Argentino Roca, en Acuerdo General de Ministros (M. García Merou, E. Berduc, Felipe Yofre, Pablo Riccheri, A. Alcorta), Buenos Aires, 20 de noviembre de 1900.

29. BACSC, Caja 47: “Copia Fiel”, Informe al Ministro de Agricultura, Martín García Merou, Buenos Aires, 8 de octubre de 1900.

30. BACSC, Caja 47: "Carpeta Tacaaglé”, Capellán P. Guido Depedri, Corrientes, al Ministerio de Agricultura, sobre ampliación de la superficie concedida para la fundación de la Misión de San Francisco Solano, sobre el Río Pilcomayo, 24 de setiembre de 1902. .

31. BACSC, Caja 47: "Copia Fiel”, Fray Pedro Iturralde, en nombre y representación de Fray Gabriel Grotti, Prefecto de las Misiones del Colegio de la Merced de Corrientes, Buenos Aires, al Ministro de Agricultura Wenceslao escalante, Buenos Aires, 13 de agosto de 1901. También BACSC, Caja 47: "Copia Fiel”, Informe de la Dirección de Tierras y Colonias, Ybargúren, Buenos Aires, 16 de agosto de 1901.

32. BACSC, Caja 47: "Carpeta Tacaaglé", Carta enviada al Ministerio de Agricultura por el Fray Pedro Iturralde, Buenos Aires, 20 de mayo de 1932.

33. BACSC, Caja 47: "Carpeta Tacaaglé", Comisario General, Prefecto Fray Gabriel Grotti, Prefectura de los R. P. Misioneros Franciscanos, Corrientes, La Merced, nombramiento de Fray Guido Depedri para que se traslade a la Capital Federal, Misión de Indígenas sobre el río Pilcomayo, Formosa, 3 de setiembre de 1902. 
34. BACSC, Caja 47: Tacaaglé, Carpeta 1914, Expediente № 2851/M. Ministerio de Agricultura, sobre ampliación de la superficie concedida para la Misión de San Francisco Solano de Tacaaglé, Fray Pedro Iturralde, 1902.

35. BACSC, Caja 47: Tacaaglé, № 2851/M/1902, Copia Expediente del cambio de ubicación y ampliación de la superficie de 60.000 hectáreas por otra de 40.000 en la Misión de Tacaaglé presentado por Fray Guido Depedri, miembro del Colegio de Propaganda Fide de los Misioneros Franciscanos de Corrientes, y representante del Prefecto Gabriel Grotti, a la División de Tierras y Colonias del Ministerio de Agricultura, sobre ampliación de la superficie concedida para la Misión de San Francisco Solano de Tacaaglé, Fray Pedro Iturralde. También véase BACSC, Caja 47: “Carpeta Tacaaglé”, Copia Fiel del Expediente № 2851/M/1902, Ministerio de Agricultura, sobre ampliación de la superficie concedida para la Misión de San Francisco Solano de Tacaaglé, sobre el Río Pilcomayo (Fray Pedro Iturralde, 15 de diciembre de 1914).

36. BACSC, Caja 47: “Carpeta Tacaaglé", Decreto de atribución a la Misión Tacaaglé del 15 de noviembre de 1902, Presidente Nacional de la República Argentina a Misioneros Franciscanos del Colegio de la Merced de la Provincia de Corrientes.

37. BACSC, Caja 47: “Carpeta Tacaaglé”, Antonio J. Carballo, Buenos Aires, 1 de diciembre de 1902, Geodecia, Octavio S. Pico.

38. BACSC, Caja 47: "Carpeta Tacaaglé", Carta enviada al Ministerio de Agricultura por el Fray Pedro Iturralde, Buenos Aires, 20 de mayo de 1932.

39. BACSC, Caja 47: "Copia Fiel”, Intercambio entre el Ministro de Agricultura, Exequiel Ramos Mejía, y la Dirección General de Tierras y Colonias, P. Ezcurra, Buenos Aires, 23 de julio y 25 de julio de 1907. También véase BACSC, Caja 47: “Copia Fiel”, Informe 655, Ramos Muñoz, al Director de Tierras y Colonias, Buenos Aires, 9 de agosto de 1907.

40. BACSC, Caja 47: "Copia Fiel”, Dirección General de Tierras y Colonias, B. Decoud, al Ministro de Agricultura, Pedro Ezcurra, solicitud de la Misión San Francisco Solano, Fray Guido Dapadri, Prefecto de Misiones, Buenos Aires, 22 de setiembre de 1909.

41. BACSC, Caja 47: “Copia Fiel”, Dirección General de Tierras y Colonias, A. Margueirat, Buenos Aires, 31 de octubre de 1910.

42. BACSC, Caja 47: "Carpeta Tacaaglé”, Informe de Fray Rafael Gobelli, Comisario y Superior de las Misiones Franciscanas, al Ministro, Buenos Aires, 30 de diciembre de 1914.

43. Los resultados pueden consultarse en BACSC, Caja 47: "Carpeta Tacaaglé", Dirección General de Tierras y Colonias del Ministerio de Agricultura, № 844, Cop. I, ph. 94, 1915.

44. BACSC, Caja 47: "Carpeta Tacaaglé", Informe de Fray Rafael Gobelli, Comisario y Superior de las Misiones Franciscanas, al Ministro, Buenos Aires, 30 de diciembre de 1914.

45. BACSC, Caja 47: "Carpeta Tacaaglé", Carta enviada al Ministerio de Agricultura por el Fray Pedro Iturralde, Buenos Aires, 20 de mayo de 1932 (defensa de la Misión San Francisco Solano de Tacaaglé del riacho El Porteño). También véase BACSC, Caja 47: “Carpeta Tacaaglé, Decreto firmado por el Ministro de Agricultura el 19 de abril de 1915 (Exp. 575-I-L915); Copia para Fray Pedro Iturralde, Dirección de Tierras y Colonias, Buenos Aires, abril de 1915.

46. BACSC, Caja 47: Carpeta Tacaaglé, Carta enviada al Ministerio de Agricultura por el Fray Pedro Iturralde, Buenos Aires, 20 de mayo de 1932.

47. BACSC, Caja 47: "Carpeta Tacaaglé", Ministerio de Agricultura de la República Argentina, Expediente 75-I-1915, Buenos Aires, 19 de abril de 1915.

48. BACSC, Caja 47: Tacaaglé, Carpeta 1917-1918, Carta de Fray José Zurflüh, Misión Franciscana Tacaaglé (Pilcomayo), a Fray Antonio Pighín, San Martín Norte, 16 de julio de 1925. Carta reproducida a Fray Joaquín María Ducca, Colonia Dolores, 29 de julio de 1925.

49. BACSC, Caja 47: Carpeta Tacaaglé, Carta enviada al Ministerio de Agricultura por el Fray Pedro Iturralde, Buenos Aires, 20 de mayo de 1932.

50. BACSC, Caja 47: Carpeta Tacaaglé, Carta enviada al Ministerio de Agricultura por el Fray Pedro Iturralde, Buenos Aires, 20 de mayo de 1932. 
51. BACSC, Caja 16: Circulares de Superiores Religiosos, Fray Carlos Brollo, Director, San Lorenzo, 22 de mayo de 1960.

\section{RESÚMENES}

La Misión Indígena fue inaugurada en el año 1901, en la zona del río Pilcomayo del Territorio Nacional de Formosa, precisamente al costado de la concesión paraguaya otorgada a Elisa (Elizabeth Alicia) Lynch. Desde entonces, fue trasladada, primero a Tacaaglé en 1902, donde adquirió el nombre de Misión San Francisco Solano, y posteriormente, en 1915, al riacho El Porteño. Los Misioneros Franciscanos asumieron la tarea de formar a "colonos indígenas" tobas y pilagás para la producción de azúcar. Se analiza la evolución de la Misión Franciscana y el impacto de la llegada del Ferrocarril de Formosa a Embarcación (F.C.F.E.). La documentación utilizada se encuentra en la Biblioteca y Archivo Históricos de la Provincia Franciscana de San Miguel, del Museo Conventual de San Carlos Borromeo ubicado en San Lorenzo, Provincia de Santa Fe.

The Indigenous Mission was inaugurated in the year 1901, in the zone of the river Pilcomayo of the National Territory of Formosa, precisely to the side of the Paraguayan concession granted to Elisa (Elizabeth Alicia) Lynch. Since then, it was moved, first to Tacaaglé in 1902, where the name of Mission acquired San Francisco Solano, and later, in 1915, to the riacho El Porteño. The Franciscan Missionaries assumed the task of forming "indigenous colonists" tobas and pilagás for the production of sugar. There is analyzed the evolution of the Franciscan Mission and the impact of the arrival of the Ferrocarril Formosa a Embarcación (F.C.F.E.). The used documentation is in the Biblioteca y Archivo Históricos de la Provincia Franciscana de San Miguel, del Museo Conventual de San Carlos Borromeo located in San Lorenzo, Provincia de Santa Fe.

\section{ÍNDICE}

Keywords: Tacaaglé, Indigenous Mission, Formos, Franciscan Missionaries, fiscal land Palabras claves: Tacaaglé, Misión Indígena, Formosa, Misioneros Franciscanos, tierra fiscal

\section{AUTOR}

\section{GABRIELA DALLA CORTE}

Facultad de Geografía e Historia, Universitat de Barcelona, España. Correo electrónico: dallacorte@ub.edu 